\title{
Experimental tests of PVD AICrN-coated planer knives on planing Scots pine (Pinus sylvestris L.) under industrial conditions
}

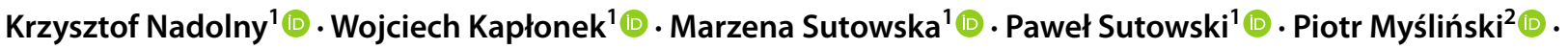 \\ Adam Gilewicz $^{3}$ - Bogdan Warcholiński ${ }^{2}$
}

Received: 23 May 2020 / Accepted: 21 January 2021 / Published online: 16 February 2021

(c) The Author(s) 2021

\begin{abstract}
Raw pine wood processing and especially its mechanical processing constitute a significant share among technological operations leading to obtaining a finished product. Stable implementation of machining operations, ensuring long-term repeatable processing results depends on many factors, such as quality and invariability of raw material, technical condition of technological equipment, adopted parameters of work, qualifications and experience of operators, as well as preparation and properties of the machining tools used. It seems that the greatest potential in the search for opportunities to increase the efficiency of machining operations has the modification of machining tools used in it. This paper presents the results of research work aimed at determining how the life of cutting tools used in planing operations of wet pine wood is affected by the application of chromium aluminum nitride $(\mathrm{AlCrN})$ coating to planar industrial planing knives in the process of physical vapour deposition. For this purpose operational tests were carried out under production conditions in a medium-sized wood processing company. The study compares the effective working time, rounding radius, the profile along the knife (size of worn edge displacement, wear area of the cutting edge), selected texture parameters of the planar industrial planing knife rake face and visual analyses of cutting edge condition of AlCrN-coated planar knives and unmodified ones. The obtained experimental results showed the possibility of increasing the life of AlCrN-coated knives up to $154 \%$ compared to the results obtained with uncoated ones. The proposed modification of the operational features of the knives does not involve any changes in the technological process of planing, does not require any interference with the machining station nor its parameters, therefore enabling rapid and easy implementation into industrial practice.
\end{abstract}

\section{Abbreviations}

AMR Automatic magnification reading

CMOS Complementary metal-oxide semiconductor

FLC Flexible LED control

HSS High-speed steel

L1 Lower cutter head 1

LED Light-emitting diode
N Modified planar industrial planing knife

NN Unmodified planar industrial planing knife

PVD Physical vapor deposition

U1 Upper cutter head 1

U2 Upper cutter head 2

$\mathrm{AlCrN}$ Chromium aluminum nitride coating

Aw Wear area of the cutting edge, $\mathrm{mm}^{2}$
Krzysztof Nadolny

krzysztof.nadolny@tu.koszalin.pl

Wojciech Kapłonek

wojciech.kaplonek@tu.koszalin.pl

Marzena Sutowska

marzena.sutowska@tu.koszalin.pl

Paweł Sutowski

pawel.sutowski@tu.koszalin.pl

Piotr Myśliński

piotr.myslinski@tu.koszalin.pl

Adam Gilewicz

adam.gilewicz@tu.koszalin.pl
Bogdan Warcholiński

bogdan.warcholinski@tu.koszalin.pl

1 Department of Production Engineering, Faculty of Mechanical Engineering, Koszalin University of Technology, Racławicka 15-17, 75-620 Koszalin, Poland

2 Department of Technical Physics and Nanotechnology, Faculty of Mechanical Engineering, Koszalin University of Technology, Racławicka 15-17, 75-620 Koszalin, Poland

3 Department of Bioengineering, Faculty of Mechanical Engineering, Koszalin University of Technology, Racławicka 15-17, 75-620 Koszalin, Poland 


\begin{tabular}{|c|c|}
\hline$A w_{(a v)}$ & $\begin{array}{l}\text { Average value of wear area of the cutting edge, } \\
\mathrm{mm}^{2}\end{array}$ \\
\hline$R a$ & $\begin{array}{l}\text { Arithmetical mean deviation of the roughness } \\
\text { profile, } \mu \mathrm{m}\end{array}$ \\
\hline$R p$ & $\begin{array}{l}\text { Maximum profile peak height within a sampling } \\
\text { length, } \mu \mathrm{m}\end{array}$ \\
\hline$R q$ & $\begin{array}{l}\text { Root mean square deviation of the roughness } \\
\text { profile, } \mu \mathrm{m}\end{array}$ \\
\hline$R t$ & Total height of profile, $\mu \mathrm{m}$ \\
\hline$R v$ & $\begin{array}{l}\text { Maximum profile valley depth within a sampling } \\
\text { length, } \mu \mathrm{m}\end{array}$ \\
\hline$R z$ & $\begin{array}{l}\text { Maximum height of the profile within a sampling } \\
\text { length, } \mu \mathrm{m}\end{array}$ \\
\hline$r_{a p}$ & Radius of the cutting edge after processing, $\mu \mathrm{m}$ \\
\hline$r_{a p(a v)}$ & $\begin{array}{l}\text { Average value of radius of the cutting edge after } \\
\text { processing, } \mu \mathrm{m}\end{array}$ \\
\hline$r_{r}$ & Reference radius of the cutting edge, $\mu \mathrm{m}$ \\
\hline$r_{r(a v)}$ & $\begin{array}{l}\text { Average value of reference radius of the cutting } \\
\text { edge, } \mu \mathrm{m}\end{array}$ \\
\hline$S a$ & Arithmetic mean deviation of the surface, $\mu \mathrm{m}$ \\
\hline$S a_{(a v)}$ & $\begin{array}{l}\text { Average value of arithmetic mean deviation of } \\
\text { the surface, } \mu \mathrm{m}\end{array}$ \\
\hline$S b i$ & Surface bearing index, - \\
\hline$S b i_{(a v)}$ & Average value of surface bearing index, - \\
\hline$S d q$ & Root-mean-square slope of the surface, $\mu \mathrm{m} \cdot \mu \mathrm{m}^{-1}$ \\
\hline$S d s$ & Density of summits of the surface, $\mathrm{pks} / \mathrm{mm}^{2}$ \\
\hline$S t$ & Total height of the surface, $\mu \mathrm{m}$ \\
\hline$S t_{(a v)}$ & Average value of total height of the surface, $\mu \mathrm{m}$ \\
\hline Str & Texture aspect ratio of the surface, - \\
\hline$S V$ & Worn edge displacement, $\mu \mathrm{m}$ \\
\hline$S V_{(a)}$ & Average value of worn edge displacement, $\mu \mathrm{m}$ \\
\hline
\end{tabular}

\section{Introduction}

An important part of the economy of many European countries is the wood processing industry (Walker et al. 2013; Schmithüsen et al. 2015), processing raw material from deciduous and coniferous trees. An important softwood obtained from coniferous trees showing high industrial significance is Scots pine (Pinus sylvestris L.). This species (Farjon 2005; Marinich and Powell 2017), occurring mainly in the northern hemisphere, is relatively easily harvested and uncomplicated in processing, whereby the best technical properties are characterized by pine wood from felled trees aged 80-120 years.

Raw pine wood processing and especially its mechanical processing (Davim 2013) constitute a significant share among technological operations leading to obtaining a finished product in the form of, for example, boards, slats, battens, beams, etc. Stable implementation of machining operations, ensuring long-term repeatable processing results depends on many factors, such as: quality and invariability of raw material, technical condition of technological equipment, adopted parameters of work, qualifications and experience of operators, as well as preparation and properties of the machining tools used (Bustos et al. 2010; Davim 2013; Keturakis et al. 2017; Darmawan et al. 2018, 2019). Not all factors determining the final processing result can be influenced in a controlled way. Due to the "natural" character of pine wood raw material, some of its features are difficult to predict. They can be, for example, heterogeneity of wood, occurrence of knots, twisted fibers, cracks, irregular structure of growth rings (Sandberg and Söderström 2006; Berthier et al. 2001; Axelsson 2012a, b, Altgen et al. 2017). However, it seems that the greatest potential in the search for opportunities to increase the efficiency of machining operations has the modification of the machining tools used.

An analysis of the state of the art in the use of anti-wear PVD coatings (Aihua et al. 2012; Twardowski et al. 2015; Nieslony et al. 2016; Liu et al. 2018), especially on woodworking tools (Faga and Settineri 2006; Warcholinski et al. 2011; Gilewicz et al. 2013; Kong et al. 2018) has shown significant possibilities to influence their performance, mainly to increase their life. For many years, there has been an increase in the proportion of manufacturers with coated tools on offer. This is due to several reasons, including:

(a) The coating forms a thermal barrier separating the processed material from the knife shaft. This allows the use of, for example, higher feed speed, i.e. the efficiency of the machining process is increased;

(b) The coating is generally less rough than uncoated tools. This increases the working time of the tool;

(c) Subsequent sharpening of a coated tool does not deteriorate its properties and it can process the same amount of wood raw material as after the first sharpening, with a much longer life than uncoated tool (Warcholinski and Gilewicz 2011);

(d) The surface quality of the treated wood is significantly better compared to uncoated knives (Warcholinski et al. 2011);

(e) The coating is significantly harder than the tool. Coated tools allow the use of much more difficult working conditions.

The above indicates that coated tools are/can be more effective in the material processing. An increase in the life of the tool extends the time of the inter-operational service related to, for example, replacement of the cutting head containing sharpened tools.

However, known sources still lack multi-criteria verification of the coating effect on planing tools based on research carried out in industrial conditions, significantly different from laboratory experiments. It doesn't mean that such verification is not carried out, it is usually the know-how of 
companies from the wood processing branch. A set of such practical knowledge as a rule is not patented, but proprietary and classified information. Sometimes some of its elements are published, but provided information is very general.

The essence of the processing of wood and wood-like materials is the dry processing. The temperature at the edge of the blade is up to $800-900{ }^{\circ} \mathrm{C}$ (Grobelny 1999). Authors of previous works show that the cutting edge of uncoated knives may show plastic deformation during wood processing (Porankiewicz et al. 2015; Warcholinski and Gilewicz 2011; Warcholinski et al. 2011) and the resulting significant reduction in the hardness of the knife in the cutting edge is observed (Warcholinski et al. 2011). In order not to lower the parameters of wood processing, a protective coating should be applied on the rake face of the tool to reduce the above effect. Aluminium coatings-AlTiN and AlCrN are characterized by a much higher resistance to oxidation compared to two-component coatings: $\mathrm{CrN}$ or TiN. It is around $800^{\circ} \mathrm{C}$ and $950{ }^{\circ} \mathrm{C}$, respectively. In addition, the hardness at high temperature $\left(700^{\circ} \mathrm{C}\right)$ is definitely higher for $\mathrm{AlCrN}$ coatings and is about $24 \mathrm{GPa}$ (decrease by about $25 \%$ ) compared to $\mathrm{CrN}$-about $8 \mathrm{GPa}$ (decrease by about $60 \%$ ) (Barshilia et al. 2006). Bobzin (2017), referring to the data of Oerlikon Balzers, the manufacturer of coated tools, indicates that Ti-based coatings have a hardness of about $2400 \mathrm{HV}$ at the temperature of $800{ }^{\circ} \mathrm{C}$, while AlCrN coatings at $1100{ }^{\circ} \mathrm{C}$ (Bobzin 2017). The coatings with good adhesion to the substrate and high hardness over a wide temperature range should ensure effective tool operation.

This paper presents the results of research work aimed at determining how the life of cutting tools used in planing operations of wet pine wood is affected by the application of chromium aluminium nitride ( $\mathrm{AlCrN}$ ) coating to knives in the process of physical vapour deposition (PVD). For this purpose, a number of operational tests were carried out under production conditions in a medium-sized wood processing company. The study compared the effective working time of AlCrN-coated planar knives and unmodified knives [standardly used in the wood processing industry for pine wood planing operations (Malkoçoğlu 2007; Axelsson 2012b)]. Cutting blades before and after work were also analysed in detail for both groups of tools, determining their rounding radius, the profile along the knife (size of worn edge displacement, wear area of the cutting edge), determining the values of selected texture parameters of the planar knife rake surface and performing visual analyses of cutting edge condition (with the use of stylus/optical profilometry and digital microscopy).

The aim of this study was to evaluate the life of knives modified with AlCrN coating. There are works on the use of two-component coatings, for example CrN (Beer et al. 1999; Nouveau et al. 2005; Kong et al. 2018) and TiN (Djouadi et al. 1999; Okai et al. 2006; Darmawan et al. 2008) and titanium based three- and more-component coatings-(Ti, Zr)N, TiSiN, TiBON (Pinheiro et al. 2009; Kazlauskas and Keturakis 2015; Fahrussiam et al. 2016; Darmawan et al. 2010) and chromium-CrSiN, CrCN, CrAlN (Benlatreche et al. 2009; Nouveau et al. 2007, 2009) and other. However, the AlCrN coatings described in the above works were formed only by magnetron sputtering (Benlatreche et al. 2009; Nouveau et al. 2007, 2009). It is known that the coatings synthesized by the cathodic arc evaporation method (due to the higher energy of the ions) are characterized by better mechanical properties and higher density (Fuentes et al. 2005). Therefore, a set of coatings was produced using the cathodic arc evaporation method. One of them, characterized by the best mechanical properties and wear resistance, was used for woodworking tools. Due to the cell structure of wood and its hygroscopicity, the processing of wood and wood-like materials is carried out without the use of cooling agents and lubricants. As a result, the temperature of the knife blade can reach $800-900{ }^{\circ} \mathrm{C}$ (Grobelny 1999). AlCrN coatings are characterized by a much higher resistance to oxidation compared to two-component coatings: $\mathrm{CrN}$ or TiN.

\section{Materials and methods}

\subsection{Characteristics of the AICrN coating}

Many coatings were applied to tools for woodworking and tested with different results. Due to the cell structure of wood and its hygroscopicity, the processing of wood and wood-like materials is carried out without the use of cooling and lubricating agents. As a result, the temperature of the knife blade can reach $800-900{ }^{\circ} \mathrm{C}$ (Grobelny 1999).

AlCrN coatings were deposited by cathodic arc evaporation method in a semi-industrial TINA $900 \mathrm{M}$ system equipped with arc sources with $\mathrm{AlCrN}$ (70:30) alloy cathode of 99.995 purity. In the coating deposition process, planar knives (made of HS6-5-2 steel) as well as disc-shaped substrates (made of the same material) were placed in the working chamber of the technological device. The disks $32 \mathrm{~mm}$ in diameter and $3 \mathrm{~mm}$ thick were ground and polished to a roughness $R a$ of about $0.02 \mu \mathrm{m}$. These samples enabled to measure the thickness, hardness, adhesion, and above all friction and wear of the coatings using the ball-on-disc method. The coated disc-shaped substrates were used for destructive tests (adhesion, friction, wear tests) that could not be performed directly on the tools. The next stage was cleaning and washing of substrates, including ultrasonic cleaning in an alkaline bath to remove organic impurities, followed by rinsing in deionised water and drying with warm air. The substrates were placed on a rotating handle in a vacuum chamber at a distance of $180 \mathrm{~mm}$ from the 
sources of the arch. The next step before the coatings were made was ionic etching of the substrate surface in order to remove surface oxides and improve adhesion of coatings to the substrate. Ionic etching was carried out with argon and chromium ions in an argon atmosphere of $0.5 \mathrm{~Pa}$ at the substrate polarization voltage of $-600 \mathrm{~V}$ for $10 \mathrm{~min}$. The substrate temperature during deposition was about $350{ }^{\circ} \mathrm{C}$. A thin layer of chromium, about $0.2 \mu \mathrm{m}$ thick, was deposited on the substrate surface to improve adhesion of coatings. The process of $\mathrm{AlCrN}$ deposition was carried out in $4 \mathrm{~Pa}$ nitrogen atmosphere using $80 \mathrm{~A}$ arc current. Substrates were polarized with a voltage of $-100 \mathrm{~V}$. Gas pressure and gas flow (argon, nitrogen) were controlled with Baratron type capacity meter and MKS flow controller respectively. Basic parameters of the obtained coatings are presented in Table 1.

Table 1 Specification of parameters characterizing the obtained AlCrN coating

\begin{tabular}{lll}
\hline Parameter & Unit & Value \\
\hline Thickness & $\mu \mathrm{m}$ & $2.9 \pm 0.1$ \\
Hardness & $\mathrm{GPa}$ & $23.6 \pm 0.7$ \\
Young's modulus & $\mathrm{GPa}$ & $268 \pm 9$ \\
Adhesion (critical force) $L c_{2}$ & $\mathrm{~N}$ & $91 \pm 2$ \\
Friction coefficient & - & $0.67 \pm 0.01$ \\
Wear rate & $\mathrm{mm}^{3} / \mathrm{Nm}$ & $(1.5 \pm 0.4) \times 10^{-7}$ \\
$\begin{array}{l}\text { Temperature of oxidation resist- } \\
\text { ance }\end{array}$ & ${ }^{\circ} \mathrm{C}$ & 950 (Reiter et al. 2005) \\
\end{tabular}

\subsection{Operational tests conditions}

A set of eighteen planar industrial planing knives was prepared for the experimental tests. The tools (dimensions: $160 \times 30 \times 3 \mathrm{~mm}$, wedge angle: $40^{\circ}$, material: HSS) were produced by Leitz GmbH \& Co. KG (Oberkochen, Germany). Six of them were AlCrN-coated by the PVD process. Both modified and unmodified knives from the set were transferred to a wood processing industry plant for operational testing. The plant employees filled the cutter heads with knives and sharpened them under the same conditions, according to a standard procedure used in industrial practice.

It should be emphasized that the knife life tests were carried out in the wood industry plant on the production line. Hence, there were limitations in the use of methods for measuring tool wear. It was not possible to stop the wood planing process and measure tool wear parameters such as: worn edge displacement $(S V)$, wear area of the cutting edge $(A w)$, rake face wear $\left(V_{B R}\right)$ or nose width $\left(V_{B a}\right)$ (Fig. 1), due to technological regime and continuity of production. Therefore, it has been assumed that the evaluation of tool life will be carried out in accordance with the rules applicable in the company, i.e. according to subjective evaluation of the surface quality of processed wood by experienced production workers. In the tests preceding the described tests, this assessment was confirmed by measuring the surface roughness parameters of wood taken from a batch of material from the end of the tool operation.
Fig. 1 Illustration of the most important parameters of knives wear: a overall view of the knife; $\mathbf{b}$ worn edge displacement; $\mathbf{c}$ cutting edge wear parameters b

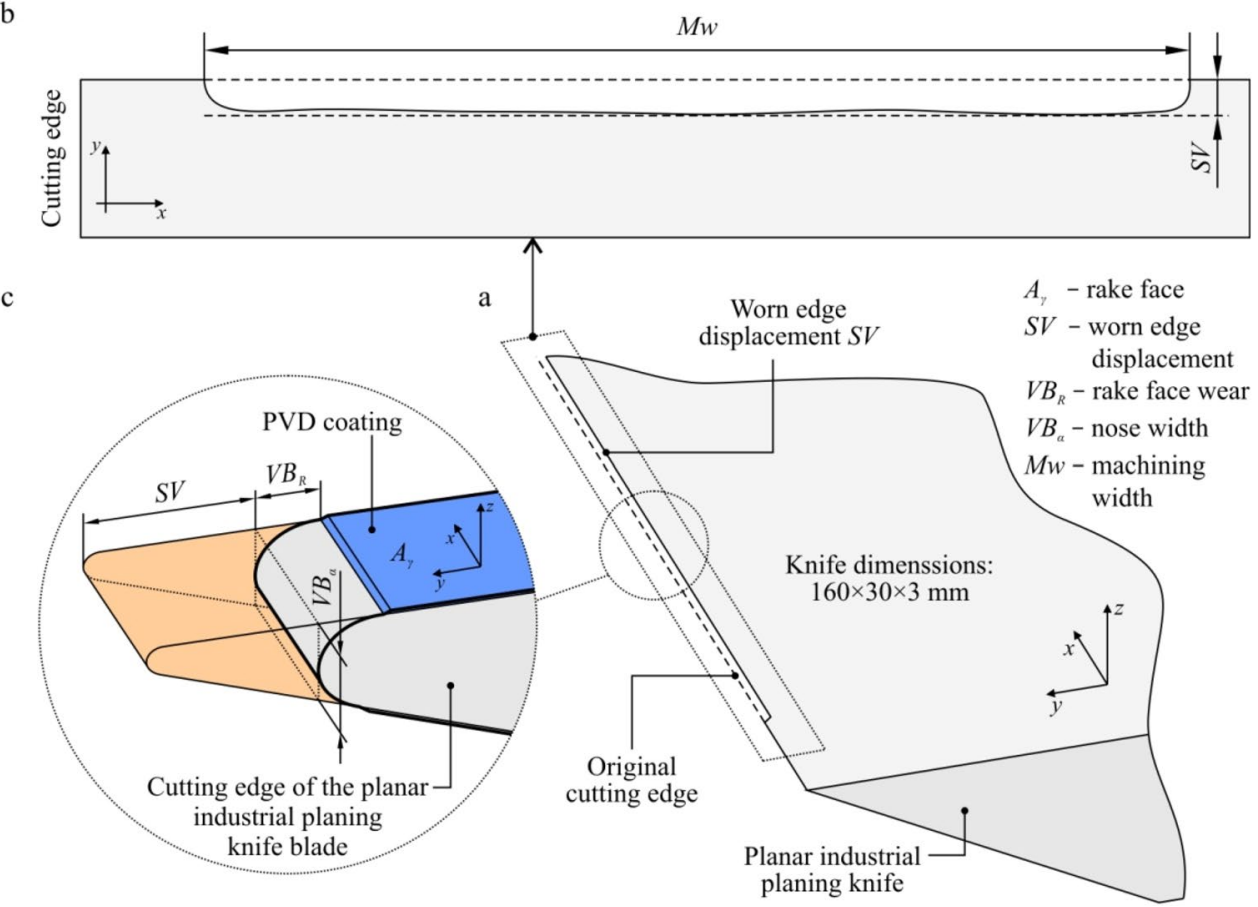


The general characteristics of planar industrial planing knives used in experimental tests with their assignment to individual cutter heads are given in Table 2.

The planing process (feed speed of $57 \mathrm{~m} / \mathrm{min}$ at a spindle speed of $6000 \mathrm{rpm}$ ) was carried out on a piece of wet pine wood (35-55\% humidity). In this case, Scots pine (Pinus sylvestris $\mathrm{L}$.) wood was used. The total machining allowance was $5 \mathrm{~mm}$. The allowance was mostly removed by the first set of milling heads during roughing. The tested planar industrial planing knives were mounted on the second (last) set of cutter heads, which realized the finishing process. Machining allowance for this operation was approximately $0.8 \mathrm{~mm}$. In Fig. 2, the operational test stand equipped with automatic feeding system for pine wood strips produced by Sacot S.R.L. (Torrebelvicino, Italy) coupled with high-speed 4-side planing machine Hydromat 22B produced by Michael Weinig AG (Tauberbischofsheim, Germany) is presented.

The experimental tests confirmed the significantly longer life of modified planar industrial planing knives (mounted in the L1) compared to unmodified ones (mounted in the U1). It should be emphasized, that at the moment, when the operator decides to end the effective planing process (based on visual analysis of the lower surface of the workpiece) using modified planar industrial planing knives, the upper surface of the workpiece planed by the second set of unmodified planar industrial planing knives still met the quality requirements.

The preparation of the planar industrial planing knives for the planing process consisted of cleaning, positioning and mounting in the cutter head as well as sharpening. The mentioned procedure was realized in the same way for all of the tools. The planing process was carried out under the same operational conditions.

\subsection{Measurements of rounding radius, worn edge displacement and wear area}

For characterization of worn level of the cutting edge of the planar industrial planing knives, four parameters were used: radius of the cutting edge measured before $\left(r_{r}\right)$ and after processing $\left(r_{a p}\right)$, worn edge displacement $(S V)$ and wear area of the cutting edge $(A w)$. The values of above parameters were obtained by a contact measuring method using stylus profilometer Hommel-Tester T8000 produced by Hommelwerke

Table 2 Characteristics of planar industrial planing knives used in experimental tests

\begin{tabular}{llll}
\hline Cutter head & AlCrN-coated & Unmodified & Planar knives designation \\
\hline U1 and U2 (upper head) & - & Yes & $\begin{array}{l}\text { Initially equipped with knives No. NN_1-NN_6 (U1), and after } \\
\text { they have worn out, another set of knives No. NN_7-NN_12 } \\
\text { (U2) }\end{array}$ \\
$\begin{array}{lll}\text { L1 (lower head) } & \text { Yes } & \text { No. N_1-N_6 }\end{array}$ \\
\hline
\end{tabular}

Fig. 2 General view of the operational test stand used for processing of the pine wood based on automatic feeding system for pine wood strips produced by Sacot S.R.L. (a) coupled with high-speed 4-side planing machine Hydromat 22B produced by Michael Weinig $\mathrm{AG}(\mathbf{b}, \mathbf{c})$

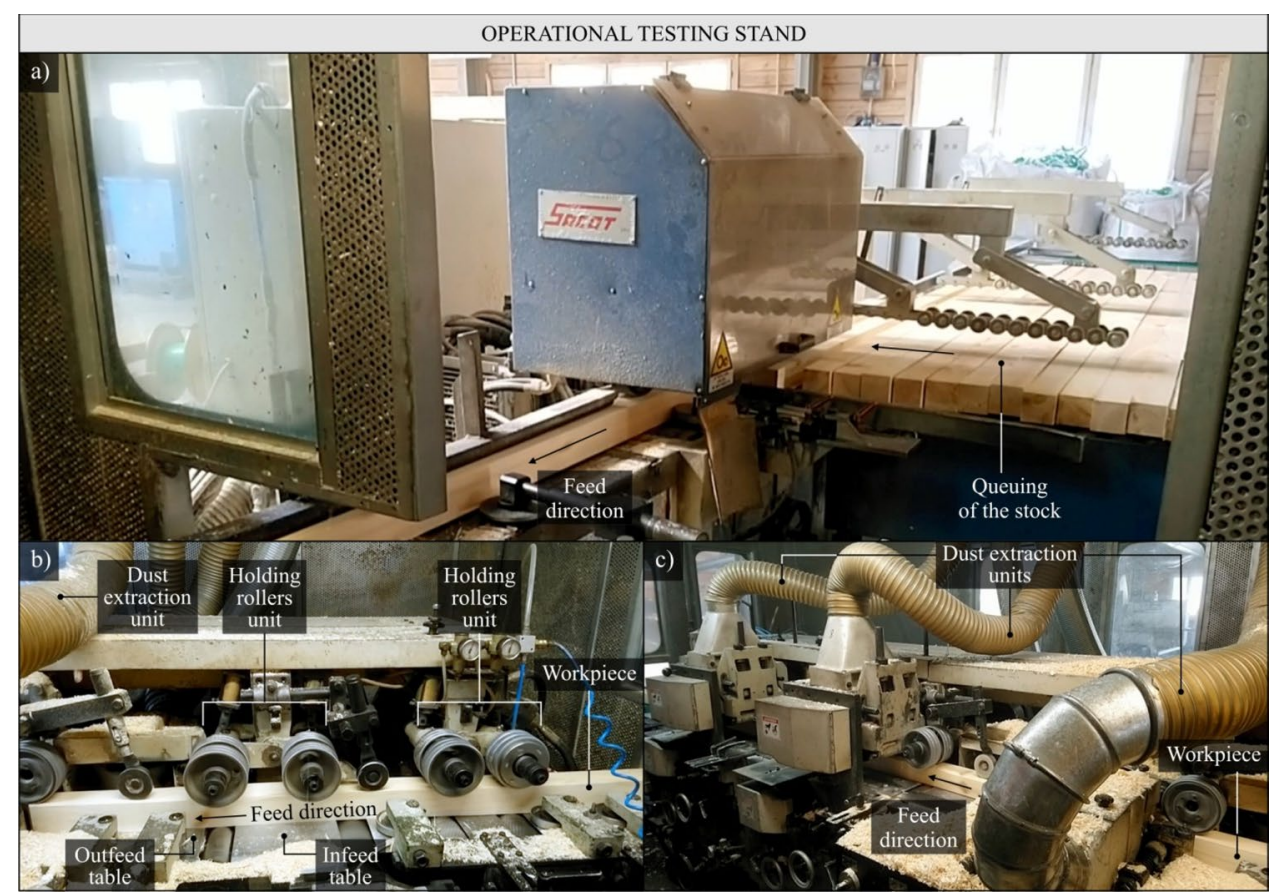


$\mathrm{GmbH}$ (Villingen-Schwenningen, Germany). The configuration of the instrument is given in Table 3.

\subsection{Measurement of surface texture of the planar industrial planing knives rake face}

For characterization of the surface texture of the planar industrial planing knives rake face, a set of selected roughness (profile) and areal (surface) parameters was used. The values of above parameters, measuring an area of $4.0 \times 4.0 \times x \times \mathrm{mm}$, were obtained by a non-contact measuring method using optical profilometer TalySurf CLI2000 produced by Taylor Hobson Ltd. (Leicester, Great Britain). The configuration of the instrument is given in Table 3, and the characteristics of used parameters are given in Table 4.

Table 3 Characteristics of instruments used in the experimental tests

\begin{tabular}{|c|c|c|c|}
\hline Instrument & Producer & Designation & Configuration and features \\
\hline Stylus profilometer & Hommel-Tester T8000 & $\begin{array}{l}\text { Hommelwerke GmbH (Villingen- } \\
\text { Schwenningen, Germany) }\end{array}$ & $\begin{array}{l}\text { Components: TKL100 pick-up with } \\
\text { a diamond stylus tip (opening } \\
\text { angle: } 90^{\circ} \text {, tip radius: } 1.5 \mu \mathrm{m} \text { ), } \\
\text { traverse unit Waveline } 60 \\
\text { Basic (tracing length: } 60 \mathrm{~mm} \text {, } \\
\text { resolution: } 0.1 \mu \mathrm{m} \text {, tracing speed: } \\
0.1-3 \mathrm{~mm} / \mathrm{s} \text { ), ver-tical displace- } \\
\text { ment column Wavelift }{ }^{\mathrm{TM}} 400 \mathrm{M} \\
\text { (max. traverse: } 400 \mathrm{~mm} \text { ), granite } \\
\text { plate Wavesystem }{ }^{\mathrm{TM}} 780 \\
\text { Software: dedicated Turbo Rough- } \\
\text { ness for Windows } 3.1 \text {, TalyMap } \\
\text { Silver } 4.1 \text { using Mountains } \\
\text { Techno-logy }{ }^{\mathrm{TM}} \text { (Digital Surf, } \\
\text { Besançon, France) }\end{array}$ \\
\hline Optical profilometer & TalySurf CLI2000 & $\begin{array}{l}\text { Taylor Hobson Ltd. (Leicester, } \\
\text { Great Britain) }\end{array}$ & $\begin{array}{l}\text { Components: LK-031 optical } \\
\text { displacement sensor (wavelength: } \\
\lambda=670 \mathrm{~nm} \text {, power: } P_{l}=0.95 \mathrm{~mW} \text {, } \\
\text { spot diameter: approx. } 30 \mathrm{~mm} \text {, } \\
\text { resolution: } 1 \mu \mathrm{m}) \text {, LK-2001 con- } \\
\text { troller (Keyence, Osaka, Japan) } \\
\text { Software: Talyscan CLI } 20002.6 \text {, } \\
\text { Taly Map Silver } 4.1 \text { using Moun- } \\
\text { tains Technology }{ }^{\mathrm{TM}} \text { (Digital Surf, } \\
\text { Besançon, France) }\end{array}$ \\
\hline Inverted metallurgical microscope & Nikon Eclipse MA200 & Nikon Corporation, (Tokyo, Japan) & $\begin{array}{l}\text { Components: } \mathrm{CFI}_{60}-2 \text { optical } \\
\text { system, revolving nosepiece with } \\
\text { T Plan EPI } 1 \times, 2.5 \times \text { and Tu Plan } \\
\text { Fluor } 10 \times, 50 \times, 100 \times \text { objective } \\
\text { lenses, DS-U2 Camera Control } \\
\text { Unit with DS-5 M 5-megapixel } \\
\text { CCD camera, observation meth- } \\
\text { ods: brightfield, darkfield, simple } \\
\text { polarizing, DIC, Epi-Fluorescence } \\
\text { Software: NIS-Elements software }\end{array}$ \\
\hline $\begin{array}{l}\text { High-resolution digital micro- } \\
\text { scope }\end{array}$ & Dino-Lite Edge AM7515MT8A & $\begin{array}{l}\text { Electronics Corp. (New Taipei } \\
\text { City, Taiwan) }\end{array}$ & $\begin{array}{l}\text { Components: 5-megapixel matrix } \\
\text { CMOS detector (image resolution: } \\
2592 \times 1944 \text { pixels, magnifica- } \\
\text { tion range of } 700-900 \times \text {, AMR } \\
\text { system), illumination: composed } \\
\text { of eight integrated LEDs with } \\
\text { flexible control of illumination } \\
\text { intensity FLC } \\
\text { Software: dedicated DinoCapture } \\
2.0 \text { software }\end{array}$ \\
\hline
\end{tabular}


Table 4 Characteristics of surface texture parameters used for characterization of planar industrial planing knives rake face

\begin{tabular}{llll}
\hline Group of parameters & Parameter & Designation & Unit \\
\hline Roughness $^{\mathrm{a}}$ & Arithmetical mean deviation of the roughness profile & $R a$ & $\mu \mathrm{m}$ \\
& Maximum profile peak height within a sampling length & $R p$ & $\mu \mathrm{m}$ \\
& Root mean square deviation of the roughness profile & $R q$ & $\mu \mathrm{m}$ \\
& Total height of profile & $R t$ & $\mu \mathrm{m}$ \\
& Maximum profile valley depth within a sampling length & $R v$ & $\mu \mathrm{m}$ \\
& Maximum height of the profile within a sampling length & $R z$ & $\mu \mathrm{m}$ \\
Amplitude $^{\mathrm{b}}$ & Arithmetic mean deviation of the surface & $S a$ & $\mu \mathrm{m}$ \\
& Total height of the surface & $S t$ & $\mu \mathrm{m}$ \\
Spatial $^{\mathrm{b}}$ & Texture aspect ratio of the surface & $S t r$ & - \\
& Density of summits of the surface & $S d s$ & $\mathrm{pks} / \mathrm{mm}^{2}$ \\
Hybrid $^{\mathrm{b}}$ & Root-mean-square slope of the surface & $S d q$ & $\mu \mathrm{m} / \mu \mathrm{m}$ \\
Functional $^{\mathrm{b}}$ & Surface bearing index & $S b i$ & - \\
\hline
\end{tabular}

${ }^{\text {a}}$ Parameters included in ISO 4287 (ISO 4287:1997 1997) standard

${ }^{\mathrm{b}}$ Parameters are included in the ISO 25178-2:2012 standard (ISO 25178-2:2012 2012) and EUR 15178 EN report (Stout et al. 1993)

\subsection{Microscopic observation and visual analysis of the cutting edge condition}

The contact (stylus profilometry) and non-contact (optical profilometry) measurements were complemented by microscopic observations of the cutting edge condition for all analysed planar industrial planing knives. In this case, a high-resolution digital microscope Dino-Lite Edge AM7515MT8A produced by Electronics Corp. (New Taipei City, Taiwan) was used. Additional microscopic observations using inverted metallurgical microscope Eclipse MA200 (Nikon Copr., Tokyo, Japan) were carried out at magnifications ranging from $10 \times$ to $1000 \times$.
The configuration of both instruments used is given in Table 3. Detailed observations combined with the acquisition of digital images were realized for cutting edges before (reference) and after-process condition.

\section{Results and discussion}

Discussion of the obtained results of the experimental tests was divided into the following parts relating to the analysis of:

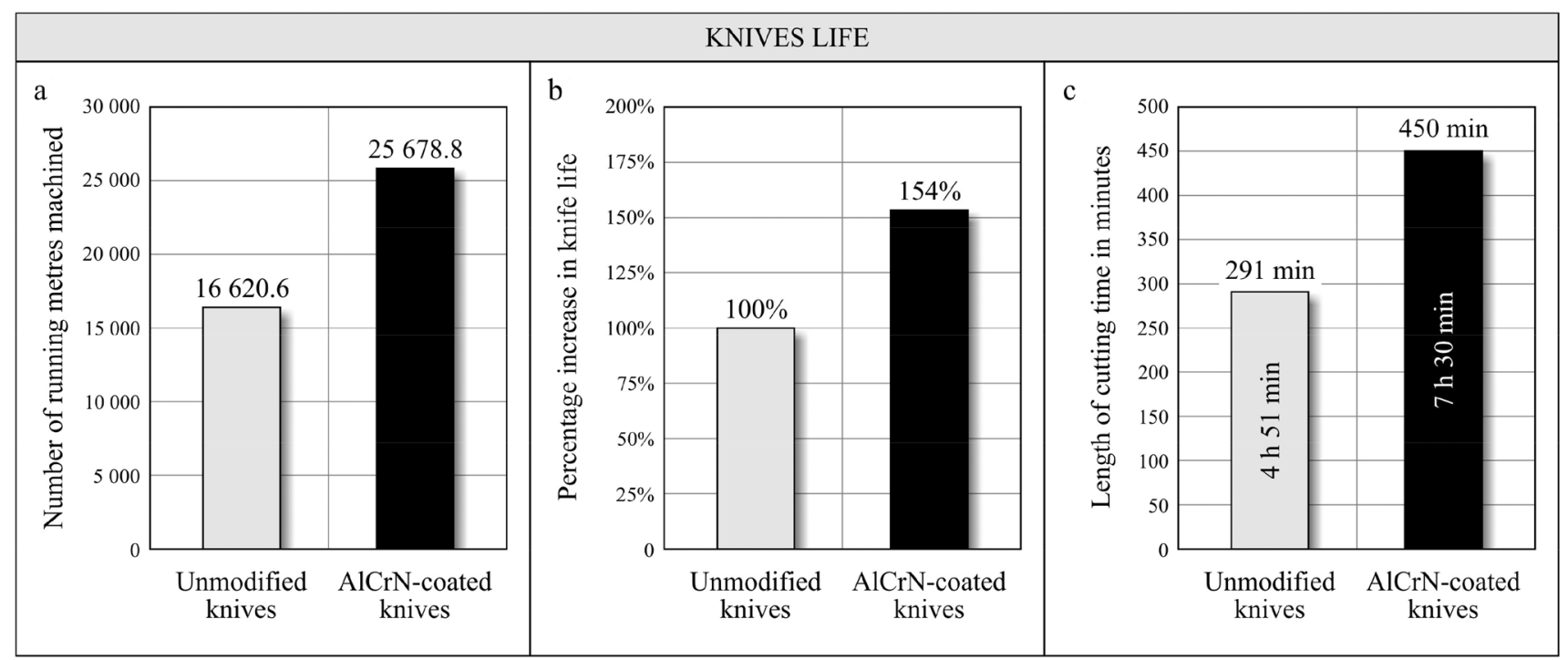

Fig. 3 Comparison of the number of running meters of the wood machined (a), percentage increase in knife life (b) as well as the length of cutting time (c) using unmodified and AlCrN-coated planar knives after the experimental tests carried out under industrial conditions 


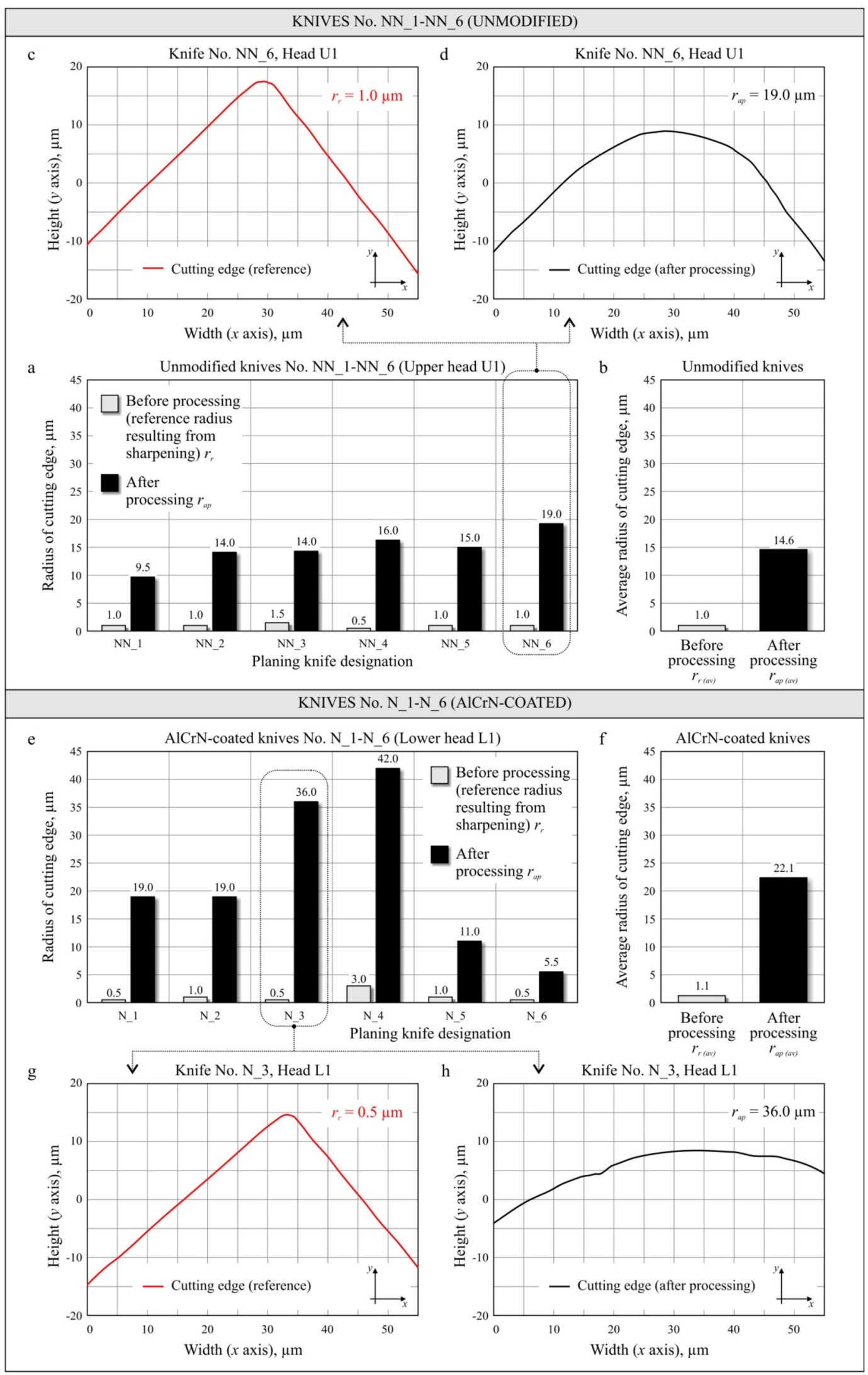


4Fig. 4 Cutting edge radii of the planar industrial planing knives for unmodified knives No. NN_1-NN_6 (a-d) and AlCrN-coated knives No. N_1-N_6 (e-h) as well as examples of measurements for specific knife before and after processing: unmodified knife No. NN_6 (c, d) and AlCrN-coated knife No. N_3 (g, h)

- life of the knives,

- radius of cutting edge in and out of the working area,

- worn edge displacement and wear area,

- texture of the knives rake face in and out of the working area,

- microscopic observation of the cutting edge condition in and out of the working area.

Although a total of three heads with overall eighteen tools (according to Table 2) were used in the experimental tests, most of the analyses presented below concern six modified planar industrial planing knives (N_1-N_6, Head L1) and six reference knives (unmodified knives NN_1-NN_6, Head U1). Such a comparison is justified by the fact that the two sets of the planar industrial planing knives mentioned were operating until the end of their service life. The second set of unmodified knives mounted in the U2 head (Table 2) worked until the end of service life of AlCrN-coated knives (N_1-N_6, Head L1) without reaching total wear, and therefore does not constitute an appropriate reference for comparative analyses.

\subsection{Life of the planar industrial planing knives}

Figure $3 \mathrm{a}$ shows a comparison of the number of running meters of the material machined using unmodified and AlCrN-coated planar industrial planing knives after the experimental tests carried out under industrial conditions. In addition, it provides a summary of the percentage increase in the obtained life of modified knives (Fig. 3b) as well as the length of cutting time (Fig. 3c).

The results of experimental tests showed a significant extension of the shelf life of AlCrN-coated planar industrial planing knives. The head with mounted modified knives (Head L1) enabled to maintain the desired quality features of 25,678.8 running meters of processed pine wood in comparison to $16,620.6$ running meters of the head with unmodified knives (Head U1). This means an increase in the life of $\mathrm{AlCrN}$-coated knives up to $154 \%$ compared to the results obtained with unmodified knives (Fig. 3b). Such a significant increase in tool life translates not only into savings resulting from lower tool wear (decrease expenditure on the purchase of tools) but also into reduced production interruptions resulting from changes of cutter heads, calibration of the machining position as well as the time and costs associated with preparing the heads for operation (knife mounting in heads and knife sharpening). Therefore, taking into account all the above factors, the obtained results of the planar industrial planing knives life tests in the planing process of wet Scots pine (Pinus sylvestris L.) should be assessed as very beneficial from the point of view of carried out machining operation in the wood processing industry.

The only factor increasing the implementation costs of the proposed modification is a slight increase in knives price (about $25 \%$ ) resulting from the need to apply a protective coating on the tools. The described modification of knives, however, does not involve any changes in the technological process of planing, does not require any interference with the machining position or its parameters, enabling very quick implementation into industrial practice.

In the described studies, the cost of coating production on the TINA $900 \mathrm{M}$ semi-industrial stand calculated for a single knife was about $25 \%$ of the regular knife price. For industrial stands with a larger chamber volume and more coated tools, this cost will be even lower. In addition, longer tool life (increased productivity) and better surface quality of the wood must be taken into account. From the point of view of production process efficiency, each replacement of planer heads results in downtime of a given device (planer) or the entire production line in which the planing operation is performed. Additionally, it is necessary to take into account the reduction in costs connected with regeneration (sharpening) of knives and also with their purchase. The profitability of using more expensive knives is confirmed by the market offer of tool manufacturers. Bobzin (2017) confirms the systematic increase in interest in tools modified with hard coatings.

\subsection{The cutting edge radii}

Figure 4 shows the measurement results of the cutting edge radii of the planar industrial planing knives for unmodified knives No. NN_1-NN_6 (Fig. 4a-d) and AlCrN-coated knives No. N_1-N_6 (Fig. 4e-h). It also includes examples of measurements for specific knife before and after processing (unmodified knife No. NN_6-Fig. 4c, d, and AlCrNcoated knife No. N_3-Fig. 4g, h).

Comparison of the values spectrum of cutting edge radii in the unused zone indicates a very similar state of the blades before processing both for unmodified knives (Fig. 4a, b) and AlCrN-coated knives (Fig. 4e, f). The variation of the radius values is relatively small and all measurements ranged from 0.5 to $3.0 \mu \mathrm{m}$, with the average values for both groups of tools being almost the same: $1.0 \mu \mathrm{m}$ for unmodified knives (Fig. 4b) and $1.1 \mu \mathrm{m}$ for modified knives (Fig. 4f). This shows that the knives were properly prepared for use due to stable and reproducible sharpening conditions.

The analysis of the designated cutting edge radii in the zone after work shows significant scattering of values. In the case of unmodified knives, the radii took values from 


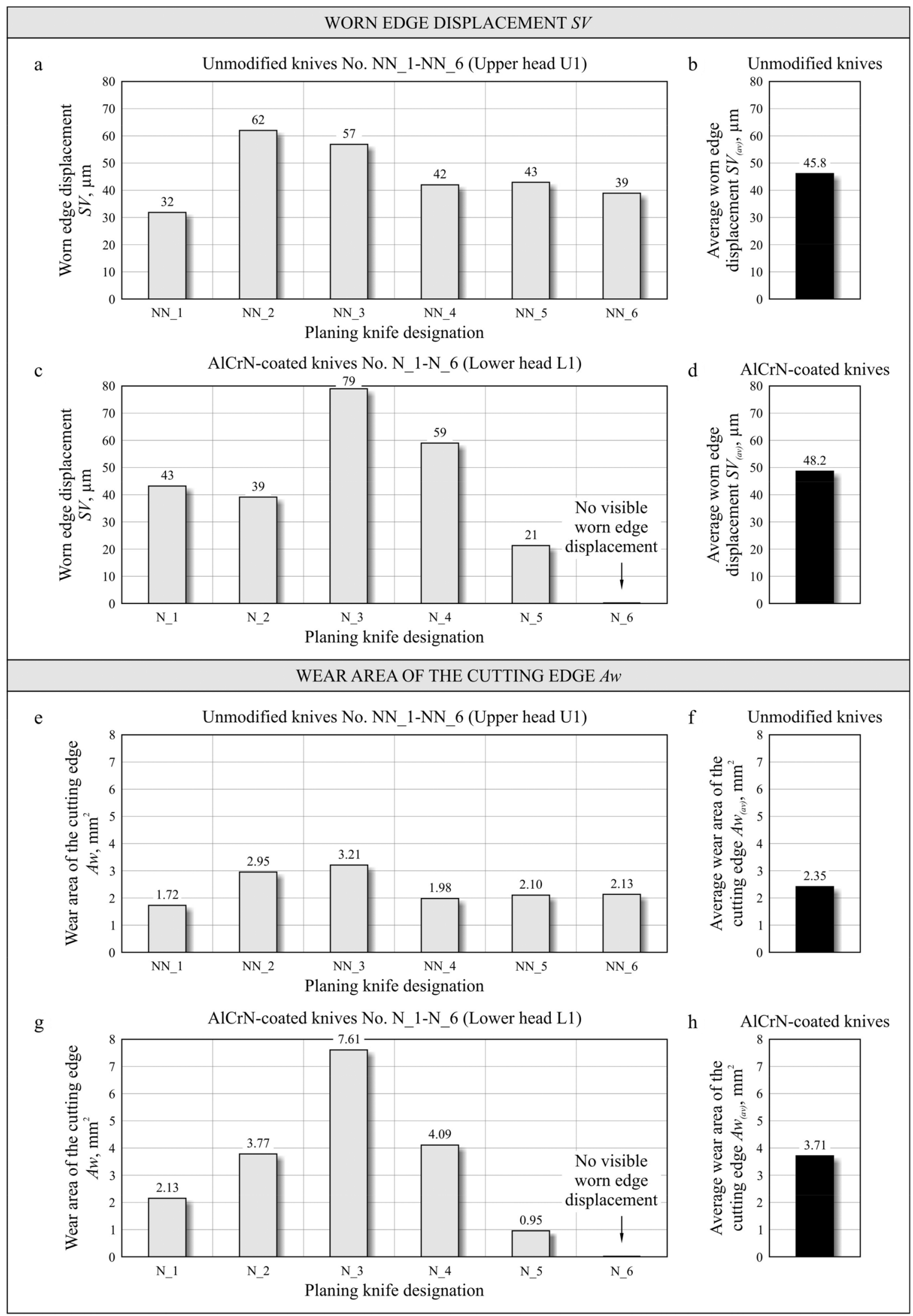


4 Fig. 5 Worn edge displacement $S V$ of the planar industrial planing knives for unmodified knifes No. NN_1-NN_6 (a, b) and AlCrNcoated knives No. N_1-N_6 (c, d) as well as wear area $A w$ of the cutting edge for unmodified knifes No. NN_1-NN_6 (e, f) and AlCrNcoated knives N_1-N_6 (g, h)

9.5 to $19.0 \mu \mathrm{m}$ (Fig. 4a), while for AlCrN-coated knives they ranged from $5.5 \mu \mathrm{m}$ to as much as $42.0 \mu \mathrm{m}$ (Fig. 4e). In the latter case, the difference between the smallest and the largest measured value is 7.6-times. This may indicate an uneven distribution of the machining allowance for the individual knives. Such a phenomenon usually results from two reasons. It may be the result of uneven extension of the knives in the cutter head or unbalance of the head and the occurrence of runout during the planing process. It seems that the first of these factors did not occur and the knives were properly positioned in the cutter heads and aligned peripherally during the grinding process.

It is more likely that the phenomenon of dynamic vibrations of a head with a significant mass rotating at $6000 \mathrm{rpm}$ is revealed. The head's runout may result from non-axial mounting on the planer spindle, but it may also be the result of wear of spindle bearings or the occurrence of other interfering factors, typical for industrial environment.

As a result, the average cutting edge radii after processing $r_{a p(a v)}$ reached $14.6 \mu \mathrm{m}$ for unmodified knives (Fig. 4b) and $22.1 \mu \mathrm{m}$ for AlCrN-coated knives (Fig. 4f). It should be stressed, however, that despite the described interfering factors and the uneven wear of individual modified knives placed in the L1 head, a significant extension of the tool life was achieved (Fig. 3). It should also be remembered that the applied methodology of experimental tests excludes the influence of variability of the processed material because both the head with modified knives and the reference knives worked simultaneously on the same material.

\subsection{Worn edge displacement}

Another very important parameter for determining the degree of blade wear is worn edge displacement $S V$ as well as wear area $A w$ of the cutting edge. The results of the measurements of these parameters are shown in Fig. 5, with the values determined for unmodified blades in Fig. 5a, b and e, $f$ and for AlCrN-coated planar industrial planing knives in Fig. 5a-d and $5 \mathrm{~g}, \mathrm{~h}$.

The analysis of the determined values of the $S V$ parameter (Fig. 5a-d) shows a similar differentiation to the values of the cutting edge radii. Unmodified knives are characterized by approximately twofold dispersion of worn edge displacement values (from $S V=32 \mu \mathrm{m}$ to $S V=62 \mu \mathrm{m}-$ Fig. 5a), while for AlCrN-coated knives, almost four-fold difference in the values of this parameter was noted for individual knives (from $S V=21 \mu \mathrm{m}$ to $S V=79 \mu \mathrm{m}-$ Fig. 5c), with the average value for both groups of tools being very similar: $S V_{(a v)}=45.8 \mu \mathrm{m}$ and $S V_{(a v)}=48.2 \mu \mathrm{m}$, respectively.

Worn edge displacement $S V$ is directly related to the wear area of the cutting edge $A w$, therefore for the latter parameter analogous relations to $S V$ have been observed (Fig. $5 \mathrm{e}-\mathrm{h}$ ). In the case of $A w$, the variation of measured values for modified knives was even greater (from $A w=0.95 \mathrm{~mm}^{2}$ to $A w=7.61 \mathrm{~mm}^{2}$-Fig. $5 \mathrm{~g}$ ). The average value of $A w$ was also significantly higher for AlCrN-coated knives $\left(A w_{(a v)}=3.71 \mathrm{~mm}^{2}\right.$-Fig. 5e) than for the set of reference knives $\left(A w_{(a v)}=2.35 \mathrm{~mm}^{2}\right.$-Fig. 5h).

In the case of both considered parameters of knife wear ( $S V$ and $A w$ ), the cause of the observed variability should be seen in the uneven load of work of individual knives mounted in the cutter head-this applies especially to the L1 head with modified knives. For one of the knives, no clearly measurable worn edge displacement was detected (knife No. N_6-Fig. 5c, g). Possible causes for this were described earlier in Sect. 3.2. They can be briefly summarized as typical aberrations from ideal laboratory conditions, whose occurrence can only be determined when carrying out tests in industrial conditions, as it was done in the described tests.

The main parameters for evaluating the wear of planar blades and the relative ratios calculated per running meter of processed wood were calculated (Table 5). Obtained results show that with the demonstrated $50 \%$ increase in knife life, there was no significant difference in the average values of radius of cutting edge after processing $r_{a p(a v)}$ and average wear area of the cutting edge $A w_{(a v)}$ with a significant (about $32 \%$ ) reduction in average worn edge displacement $S V_{(a v)}$ for $\mathrm{AlCrN}$-coated knives in relation to unmodified tools.

\subsection{Surface texture of the planar industrial planing knives rake face}

Figure 6 shows measurements results for the rake face surface texture of the planar industrial planing (unmodified) knife No. NN_2 before processing (Fig. 6a) and after processing (Fig. 6b). Analogous surface texture analyses are reproduced in Fig. 7 for AlCrN-coated knife No. N_4. Figures 6 and 7 show sample analyses that were carried out for all the planar industrial planing knives assessed and the results obtained are summarized in a consolidated form in Figs. 8 (Sa, St and Str parameters) and 9 ( $S d s, S d q$ and $S b i$ parameters). These analyses focused on six selected parameters of surface texture from the group of amplitude parameters $(S a, S t)$, spatial $(S t r, S d s)$, hybrid $(S d q)$ and functional $(\mathrm{Sbi})$, which are characterized in Table 4 . Such a wide set of surface texture parameters was used for multi-criteria evaluation of the knives rake face measurement results in the zone not in use and in the zone after work. 
Table 5 Summary of the main parameters for evaluating the wear of planar blades and the relative ratios calculated per running metre of processed wood

\begin{tabular}{|c|c|c|c|c|c|c|}
\hline \multirow[t]{2}{*}{ Parameter } & \multicolumn{2}{|c|}{ Unmodified knives } & \multicolumn{2}{|c|}{$\mathrm{AlCrN}$-coated knives } & \multirow{2}{*}{\multicolumn{2}{|c|}{$\begin{array}{l}\text { Proportion } \\
\text { of values for } \\
\text { unmodified and } \\
\text { AlCr-coated } \\
\text { knives }\end{array}$}} \\
\hline & Absolute value & Per running meter & Absolute value & Per running meter & & \\
\hline $\begin{array}{l}\text { Number of running meters of } \\
\text { the wood machined }\end{array}$ & 16,620 & - & 25,678 & - & 1.54 & $\uparrow$ \\
\hline$r_{a p(a v)}(\mu \mathrm{m})$ & 14.6 & 0.000878 & 22.1 & 0.000861 & 0.979736 & - \\
\hline$S V_{(a v)}, \mu \mathrm{m}$ & 45.8 & 0.002756 & 48.2 & 0.001877 & 0.681164 & $\downarrow$ \\
\hline$A w_{(a v)}, \mathrm{mm}^{2}$ & 2.35 & 0.000141 & 3.71 & 0.000144 & 1.021823 & - \\
\hline
\end{tabular}

The results of measurements of the basic parameter for the evaluation of the surface roughness $\mathrm{Sa}$ (arithmetic mean deviation of the surface) are presented in Fig. 8a, b, g and j. They indicate significant differentiation between individual knives in case of unmodified knives (Fig. 8a). For AlCrNcoated knives, the differences were much smaller both in relation to the surface before and after processing (Fig. 8b). From the obtained measurement results it can be concluded that the reference knives' surfaces were characterized by significantly higher arithmetic mean deviation of the rake face in both analysed zones as compared to the modified knives. This can be seen especially clearly from the average value of $S a_{(a v)}$ presented in Fig. 8j. Bearing in mind that the rake face does not undergo machining during knife sharpening, the registered differences may result from the anti-wear coating applied to the PVD process. The above observations are also confirmed by the values of the second amplitude parameter St (total height of the surface) given in Fig. 8c, $\mathrm{d}, \mathrm{h}$ and $\mathrm{k}$. In this case, the mean value determined for both analysed zones (before and after processing) of unmodified and modified knives was respectively: $S t_{(a v)}=29.70 \mu \mathrm{m}$ and $S t_{(a v)}=18.54 \mu \mathrm{m}$ (Fig. 8k).

The first spatial parameter included in the analysis was the texture aspect ratio of the surface Str (Fig. 8e, f, i, 1). This parameter is used to determine the machining traces located on the analysed surface and resulting from the treatments preceding its creation. In the analysed case, very large divergences of this parameter value were recorded in both groups of tools, up to twenty four times (Fig. 8e). This does not allow the determination of a clear trend or significant impact of the coating application. It can be assumed that such results were affected by signs of wear appearing in various forms on individual analysed surfaces. The intensity and forms of these features are further characterised in the next part of the paper (Sect. 3.5) based on the results of rake face microscopic analyses.

The second spatial parameter was the density of summits of the surface $S d s$ (Fig. 9a, b, g, j). This parameter characterizes the number of summits per unit area-in this case given in $\mathrm{mm}^{2}$. The obtained results of $S d s$ measurements were very similar for both evaluated tool zones (before and after work) and for both analysed tool groups (modified and reference). The values of this parameter were characterised by the lowest variability among all six analysed surface texture parameters. This means that in the described tests the $S d s$ parameter is not a good classifier and on the basis of its values, it is not possible to determine unequivocally the influence of the anti-wear coating application on the tool condition both before and after processing.

Hybrid parameter $S d q$ is defined as the root-mean-square slope of the surface and can be used to measure the slopes that constitute the surface and can be useful in identifying a surface with a similar average unevenness. The measurement results of this parameter are shown in Figs. 9c, d, h and k. They show that the rake face of the AlCrN-coated planar industrial planing knives have a relatively lower roughness compared to unmodified knives (Fig. 9k), similar to the results of amplitude parameter measurements ( $S a$ and $S t$ ). For all knives from set N_1-N_6 (modified knives), values of parameters $S a$ (Fig. 8b), St (Fig. 8d) and $S d q$ (Fig. 9d) increase in the zone after work, compared to the result obtained in the unused zone. This can be interpreted as a consequence of surface degradation resulting from the wear of the coating on the rake face of the analysed tools.

The last of the group of analysed parameters was the functional parameter Sbi (surface bearing index) which determines the load capacity of the measured surface. The determined values of the Sbi parameter are shown in Fig. 9e, $\mathrm{f}, \mathrm{i}$ and 1 . The observed differentiation of values did not allow to determine an unambiguous trend or dependence on the analysed input factor and the determined mean values were very similar for both groups of tools $\left(S b i_{(a v)}=0.234\right.$ for unmodified knives and $S b i_{(a v)}=0.243$ for AlCrN-coated knives-Fig. 91). 


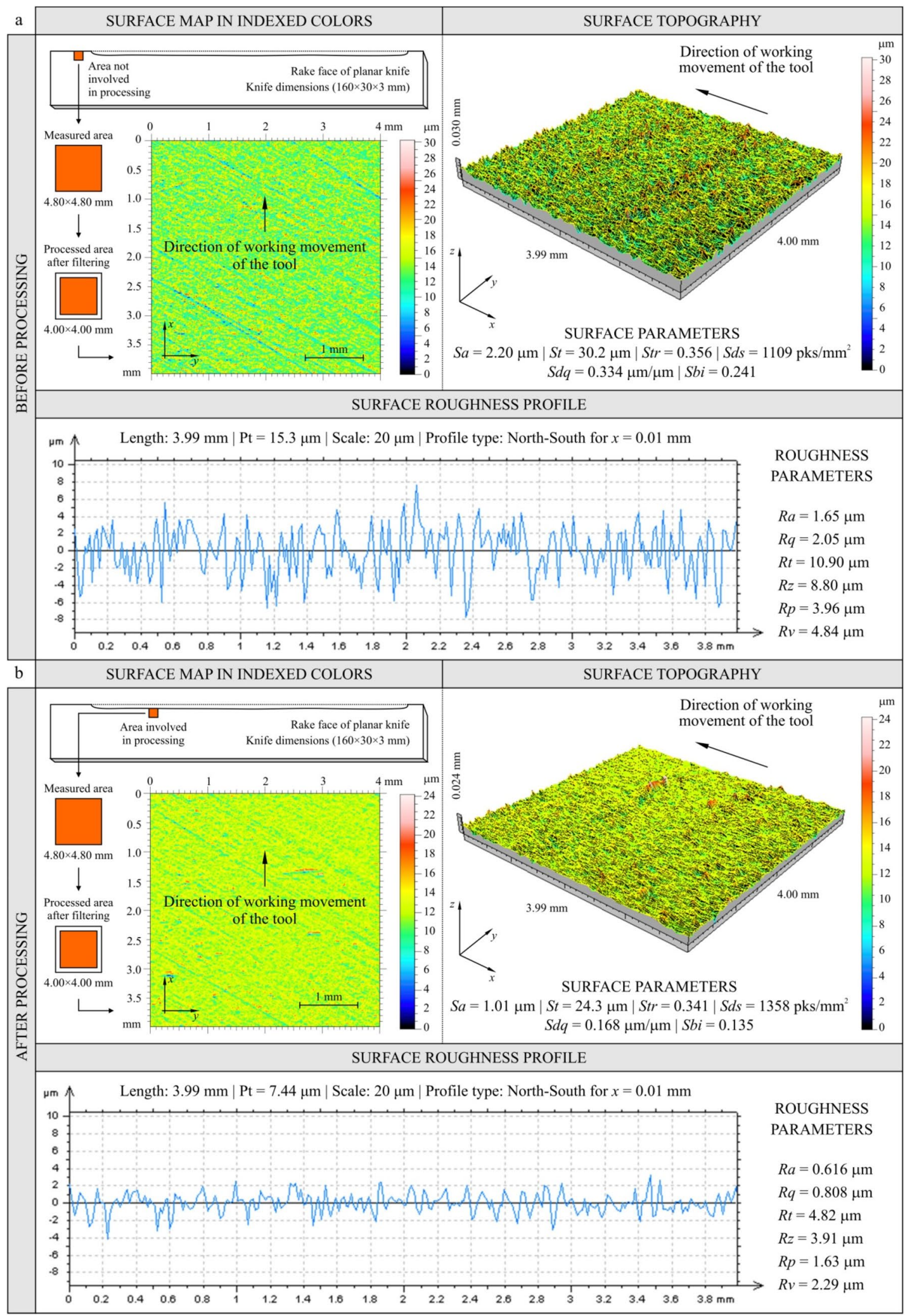

Fig. 6 Collection of measurement results obtained by the use of optical profilometer Talysurf CLI 2000 for rake face of the planar industrial planing (unmodified) knife No. NN_2 (Head U1): before processing (a); after processing (b) 


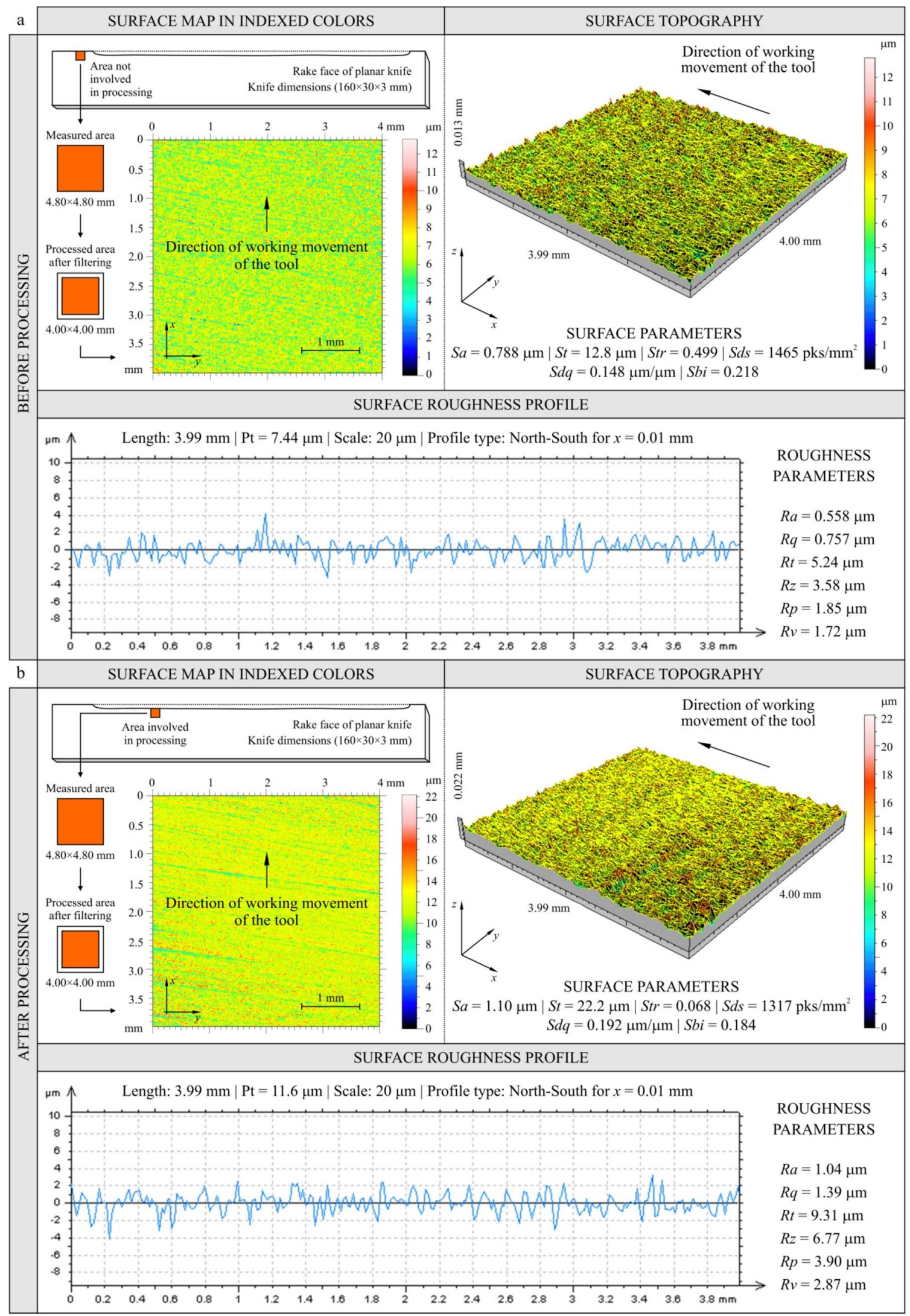

Fig. 7 Collection of measurement results obtained with an optical profilometer Talysurf CLI 2000 for rake face of the planar industrial planing AlCrN-coated knife No. N_4 (Head L1): before processing (a); after processing (b) 


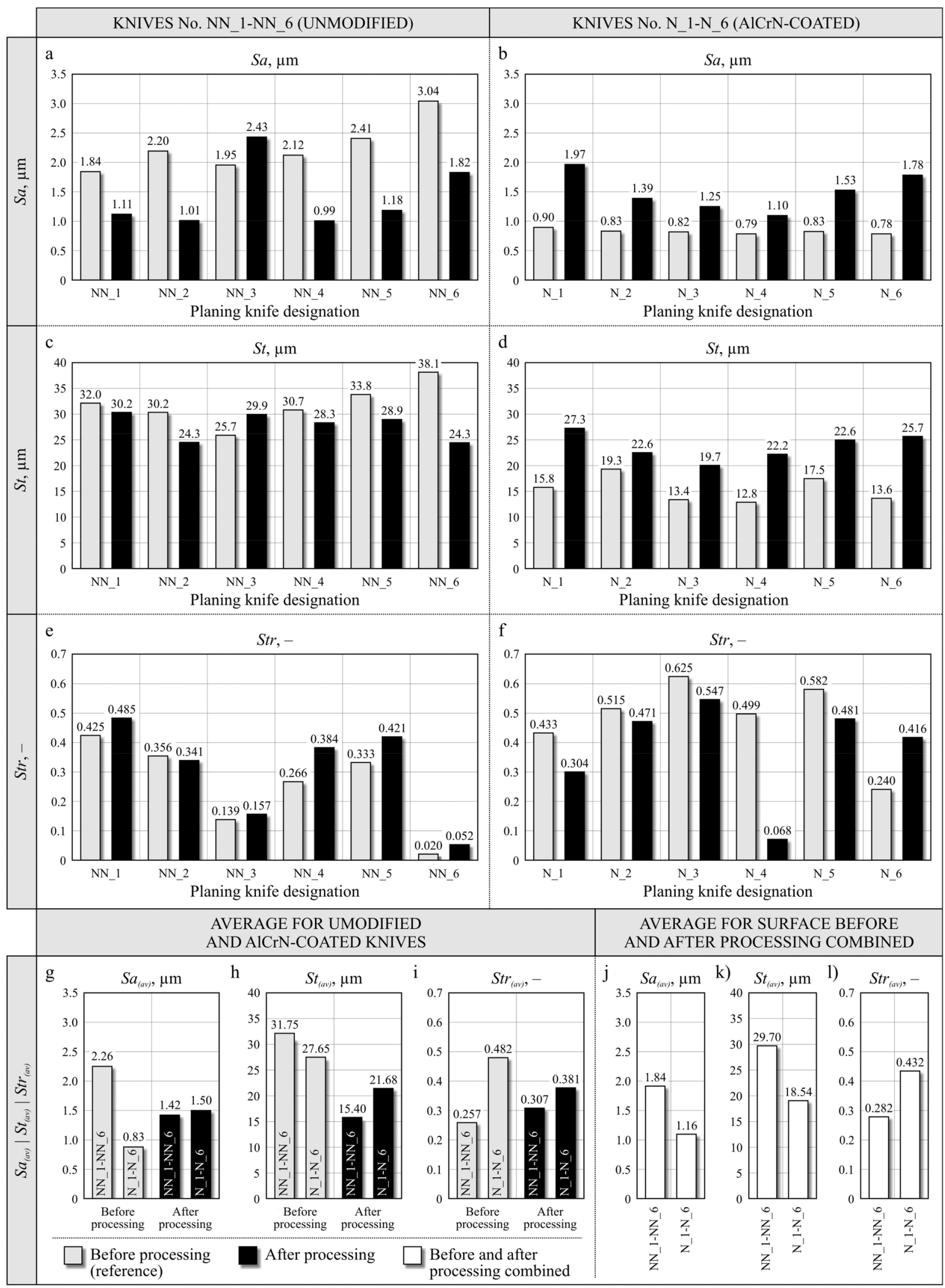

Fig. 8 Texture parameters of the planar industrial planing knife rake faces for both unmodified NN_1-NN_6 (a, c, e) and AlCrN-coated knives No. N_1-N_6 (b, d, f): $S a(\mathbf{a}, \mathbf{b}) ; \operatorname{St}(\mathbf{c}, \mathbf{d}) ; \operatorname{Str}(\mathbf{e}, \mathbf{f})$ and its average values $(\mathbf{g}-\mathbf{l})$ 


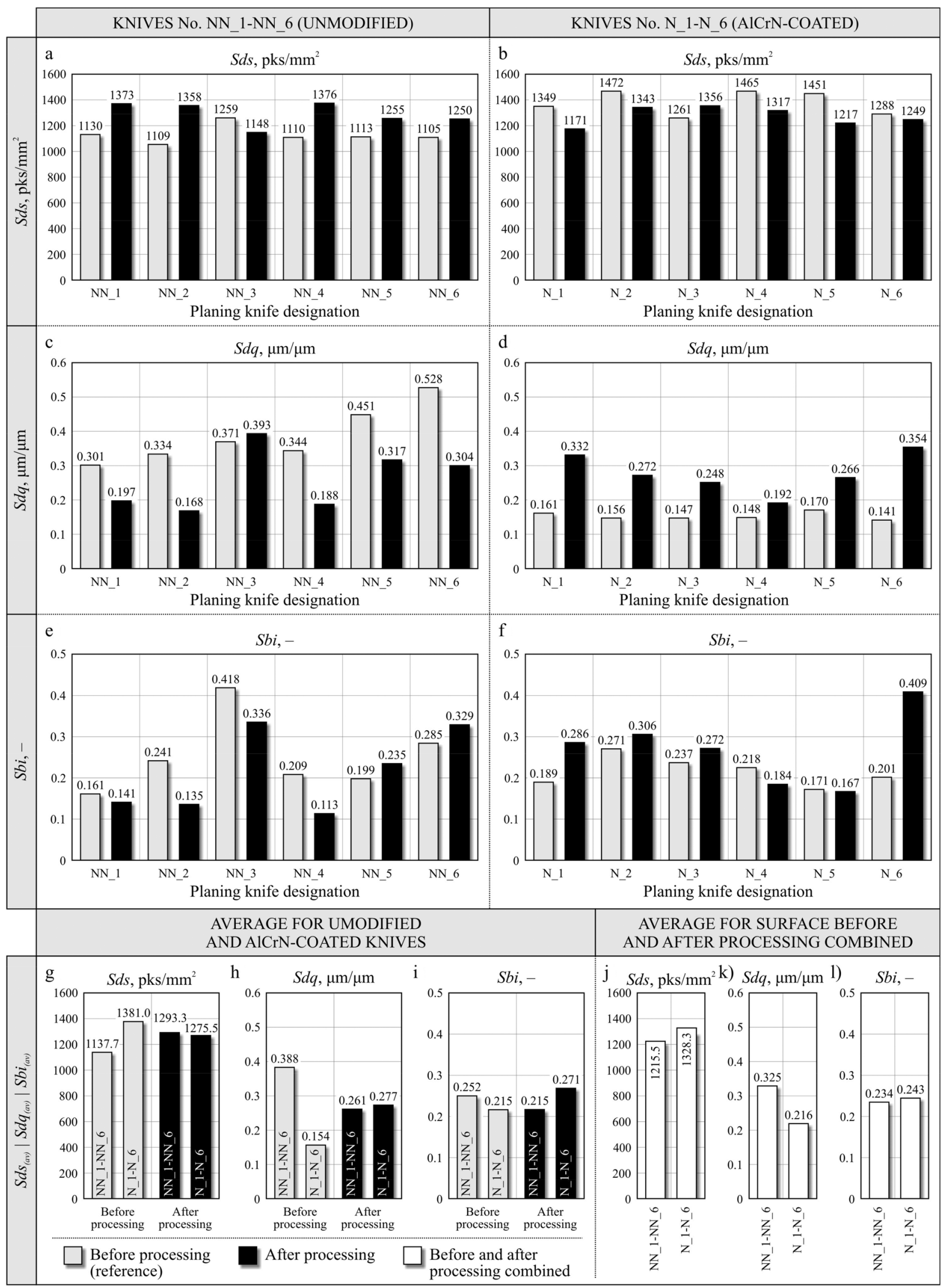

Fig. 9 Texture parameters of the planar industrial planing knife rake faces for both unmodified NN_1-NN_6 (a, c, e) and AlCrN-coated knives No. N_1-N_6 (b, d, f): $S d s(\mathbf{a}, \mathbf{b}) ; S d q(\mathbf{c}, \mathbf{d}) ; S b i(\mathbf{e}, \mathbf{f})$ and its average values $(\mathbf{g}-\mathbf{l})$ 


\section{KNIFE No. NN 10 (UNMODIFIED)}

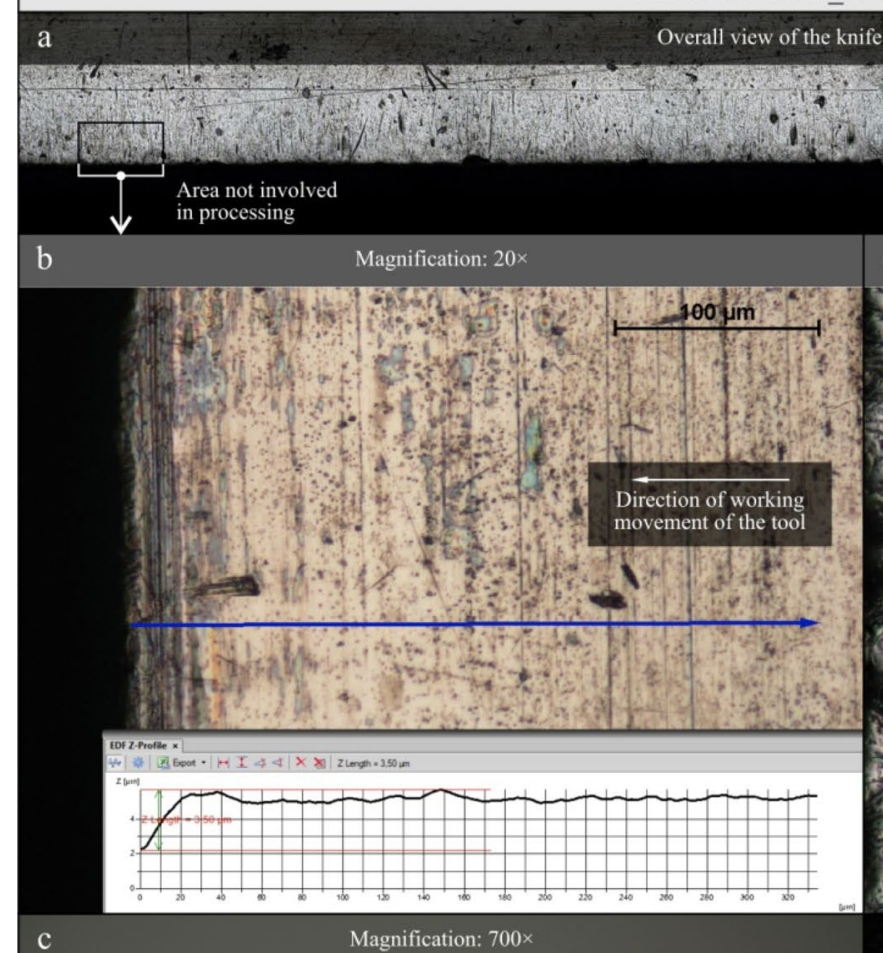

(Magnification: $5 \times$ )
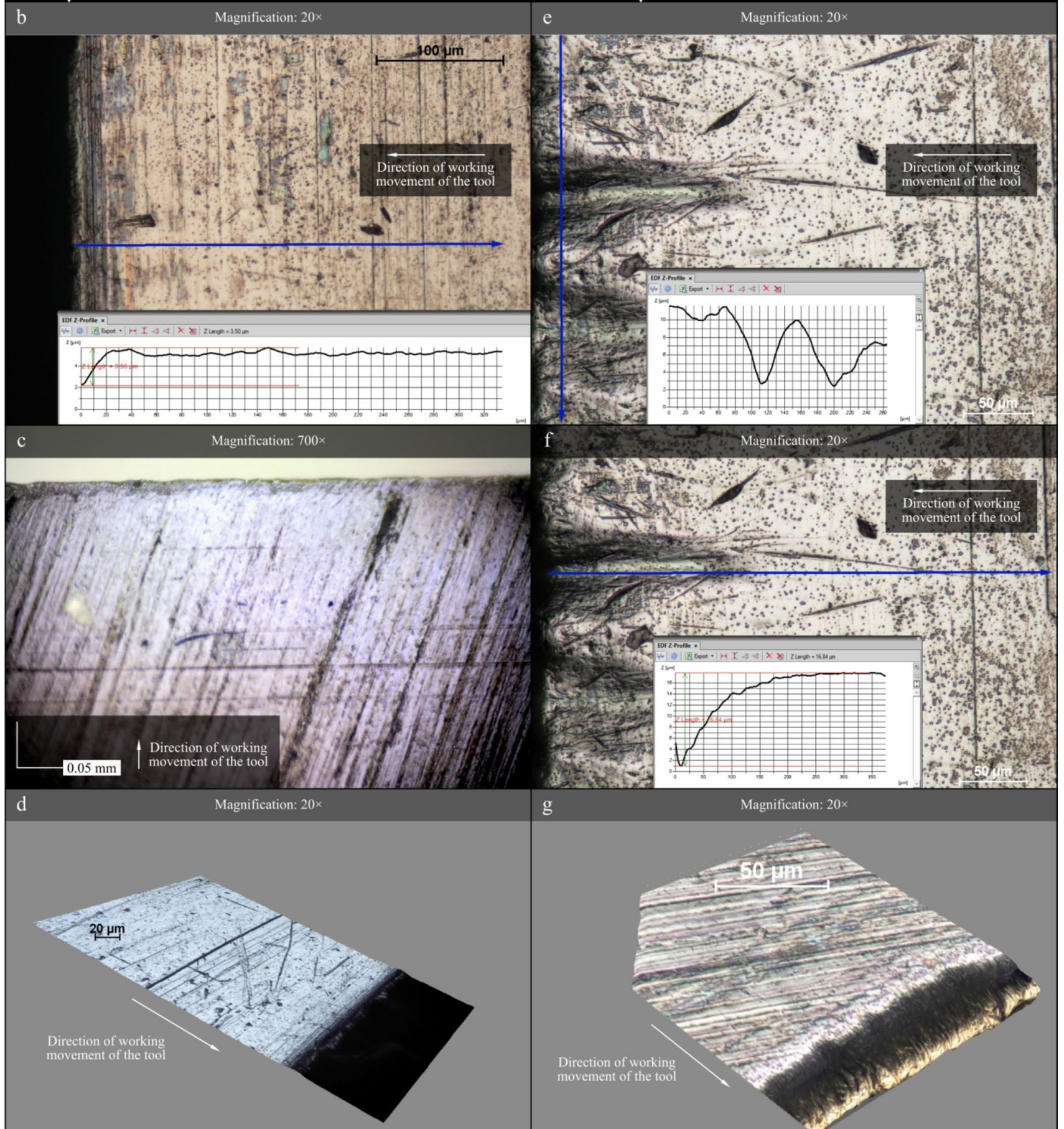

g

Magnification: $20 x$

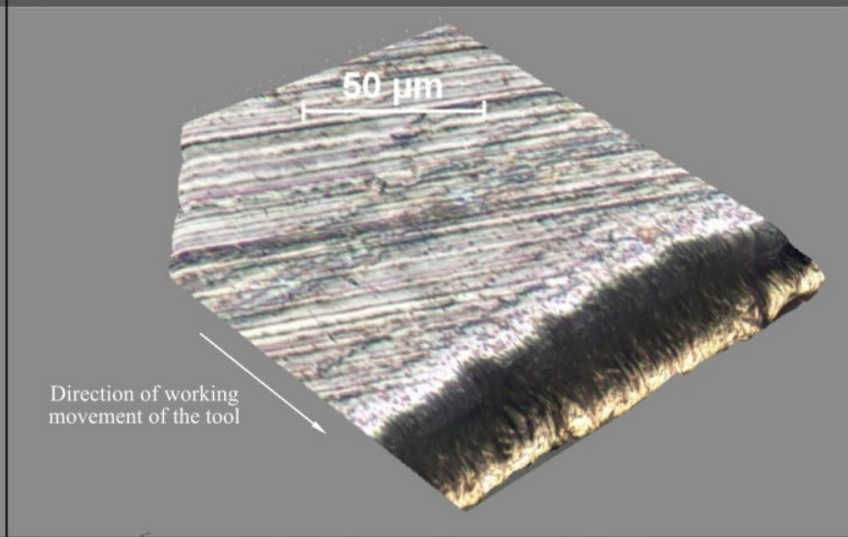

Fig. 10 Selected results of acquisition of digital images of rake face of unmodified knife No. NN_10 (a) for reference area not involved in processing (b-d) as well as for area with various visible forms of surface wear (e-g) 


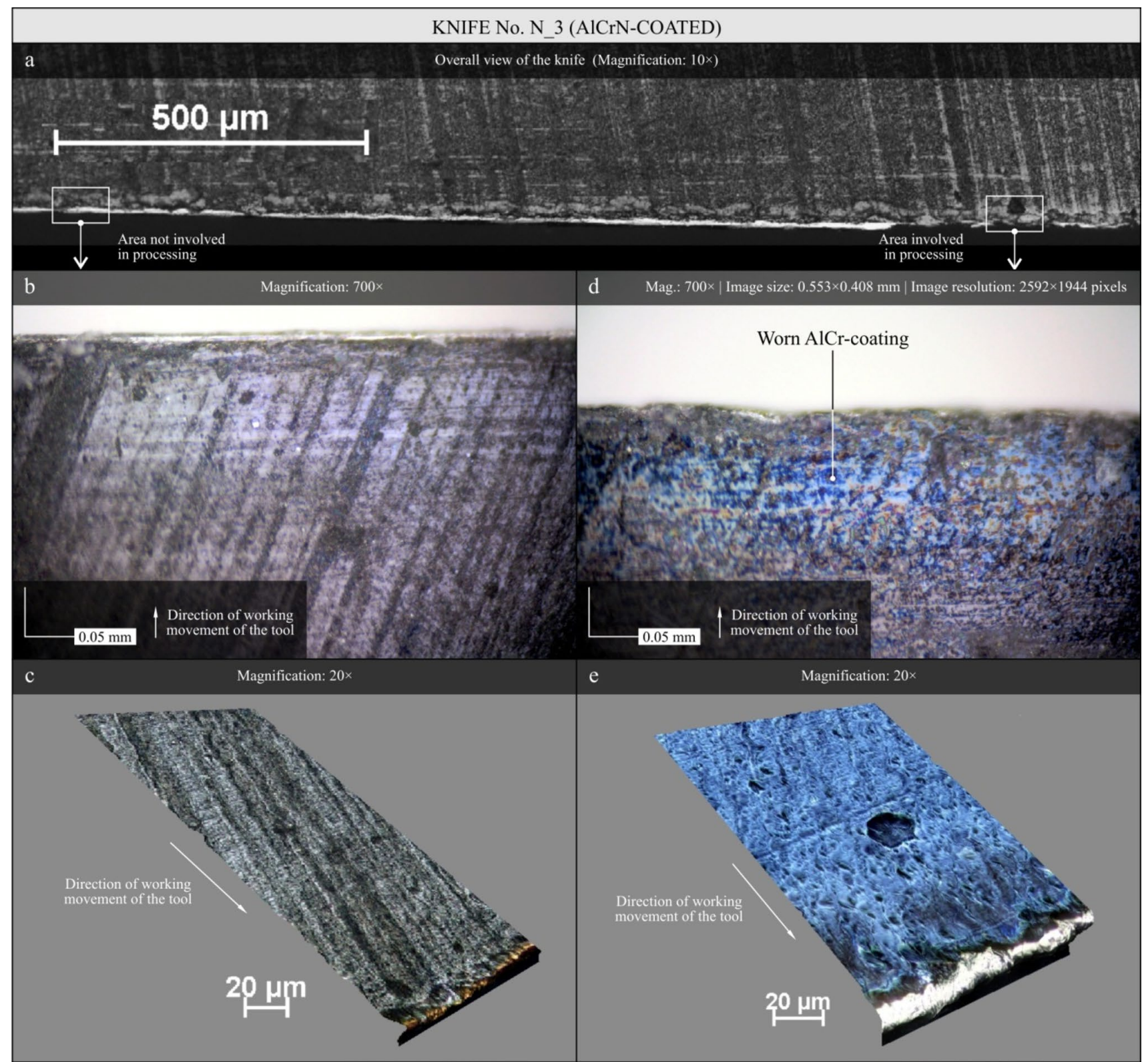

Fig. 11 Selected results of acquisition of digital images of rake face of AlCrN-coated knife No. N_3 (a) for reference area not involved in processing $(\mathbf{b}, \mathbf{c})$ as well as for area with various visible forms of surface wear $(\mathbf{d}, \mathbf{e})$

\subsection{Microscopic observation of the cutting edge condition}

The results of the parametric quantitative assessment of the results of experimental tests on Scots pine (Pinus sylvestris L.) planing process with PVD-based AlCrN-coated planar industrial planing knives operated under industrial conditions, presented in Sects. 3.1-3.4, were complemented by a qualitative assessment based on microscopic observations together with the acquisition of digital images of cutting edge. Figures 10 and 11 show selected results of acquisition of digital images of the rake face of the planar industrial planing knives. It compares the observation results of the rake face of unmodified knife No. NN_10 (Fig. 10) and AlCrN-coated knife No. N_3 (Fig. 11). Table 6 provides a summary of wear forms occurring on the rake face of all analysed planar knives including the level of its intensity.

Comparison of the number of wear forms occurring on the rake face of the assessed planar industrial planing knives and the intensity of their occurrence gives rise to the conclusion that the application of $\mathrm{AlCrN}$ coating has a positive effect on the assessed tools (Table 6). The majority of coated knives are characterized by a lower number of defects, less variety and lower intensity of their occurrence. It should be 
Table 6 Forms of wear observed on the planing knives rake face

\begin{tabular}{|c|c|c|c|c|c|}
\hline \multirow[t]{2}{*}{ Cutter head } & \multirow{2}{*}{$\begin{array}{l}\text { Planar knife } \\
\text { designation }\end{array}$} & \multicolumn{4}{|c|}{ Form of the wear } \\
\hline & & Initial lapping & Abrasive wear & Crack & Chipping \\
\hline \multirow[t]{6}{*}{ U1 (upper head) unmodified knives } & NN_1 & + & + & + & ++ \\
\hline & NN_2 & + & + & ++ & + \\
\hline & NN_3 & ++ & ++ & + & \\
\hline & NN_4 & + & ++ & ++ & \\
\hline & NN_5 & & ++ & ++ & \\
\hline & NN_6 & ++ & & ++ & + \\
\hline \multirow[t]{6}{*}{ U2 (upper head) unmodified knives } & NN_7 & + & ++ & + & ++ \\
\hline & NN_8 & & + & ++ & ++ \\
\hline & NN_9 & & & ++ & ++ \\
\hline & NN_10 & & + & + & + \\
\hline & NN_11 & & + & + & +++ \\
\hline & NN_12 & & & ++ & +++ \\
\hline \multirow[t]{6}{*}{ L1 (Lower head) AlCrN-coated knives } & N_1 & + & & ++ & ++ \\
\hline & N_2 & & & +++ & ++ \\
\hline & N_3 & + & & ++ & ++ \\
\hline & N_4 & & & & +++ \\
\hline & N_5 & & & + & ++ \\
\hline & N_6 & & & + & + \\
\hline
\end{tabular}

Surface wear intensity: +++ high, ++ moderate, + slight remembered that the visual assessment of the rake face was carried out for knives working with different times-much longer in case of AlCrN-coated knives. The results of the qualitative assessment therefore seem to fully confirm the quantitative assessment and, above all, confirm the beneficial effect of the PVD coating, which significantly reduces the occurrence of wear phenomena and enables the extension of knife life to $154 \%$ compared to unmodified knives.

It is known that sharp tools enable the machining process to be conducted over a longer time. As a rule, coated knives stay sharp longer. The coating changes the wear characteristics of the knife (including reduction in adhesion) which may reduce sticking of the workpiece residue to the tool. Extending the time between operations, for example for grinding, reduces production costs. In uncoated knives, the grain may be torn off the knife edge, which significantly worsens its cutting properties, and may even lead to the interruption of the cutting process (catastrophic wear). In coated knives, there is rather abrasion of the coating (abrasive wear).

Coated tools do not show delamination until the end of the work. The visible lack of the coating at the blade itself results from its abrasion during operation, as was also observed in Warcholinski et al. (2011). Much less chipping is observed at the edge of the blade compared to uncoated tools. Such an effect has also been observed previously by these authors (Warcholinski et al. 2011; Warcholinski and Gilewicz 2011).

\section{Conclusion}

A wide range of quantitative and qualitative analyses of Scots pine (Pinus sylvestris $\mathrm{L}$.) planing process using PVDbased $\mathrm{AlCrN}$-coated planar industrial planing knives operated under industrial conditions presented in this paper has allowed the following specific conclusions to be drawn.

1. The obtained experimental results (Sect. 3.1) showed the possibility of increasing the life of AlCrN-coated knives up to $154 \%$ compared to the results obtained with uncoated knives.

2. The analysis of cutting edge radii (Sect. 3.2), edge displacement $S V$ as well as wear area $A w$ of the cutting edge in the zone after work (Sect. 3.3) shows significant scattering of values, which may be the result of unbalance of the head and the occurrence of runout during the planing process. The head's runout may result from nonaxial mounting on the planer spindle, but it may also be the result of wear of spindle bearings or the occurrence of other undefined interference factors in industrial environment.

3. Analysis of amplitude parameters $(S a, S t)$ as well as hybrid parameter $(S d q)$ of the rake face surface texture (Sect. 3.4) revealed that the $\mathrm{AlCrN}$-coated knives have a relatively lower roughness compared to unmodified knives which may be a consequence of surface degradation resulting from the wear of the coating. 
4. The results of the qualitative assessment confirm the quantitative evaluation and, above all, confirm the beneficial effect of the PVD coating, which significantly reduces the occurrence of wear phenomena and enables the extension of the planar industrial planing knife life.

5. The applied methodology of exploitation tests excludes the influence of variability of the processed material because both the head with modified and reference planar industrial planing knife worked simultaneously on the same material.

6. Significant increase in tool life translates into savings resulting from lower tool wear (decrease expenditure on the purchase of tools), reduced production interruptions resulting from changes of cutter heads, calibration of the machining station and time and costs associated with preparing the heads for work (knife mounting in heads and knife sharpening).

7. The factor increasing the implementation costs of the proposed modification is a slight increase in the price of the planar industrial planing knives resulting from the need to apply a protective coating on the tools.

8. The proposed modification of the operational features of the planar industrial planing knives does not involve any changes in the technological process of planing, does not require any interference with the machining station or its parameters, therefore enabling rapid and easy implementation into industrial practice.

Acknowledgements The authors wish to thank the following people for their contribution in carrying operational tests and stylus/optical measurements: employees of KPPD Kalisz Pomorski, (Kalisz Pomorski, Poland)—Mr. Damian Girtler, Mr. Artur Girtler, Mr. Marcin Kruk, Mr. Marek Litwin and Mrs. Kamila Szumowicz-Włodarczyk as well as employees of Koszalin University of Technology (Koszalin, Poland) Mr. Krzysztof Maciejewski and Mr. Wojciech Zawadka, MSc, BSc.

Funding Research presented in this paper was funded by the Polish National Centre for Research and Development under project number BIOSTRATEG3/344303/14/NCBR/2018: improvement of Process and Material Efficiency in Sawmill Industry under the program BIOSTRATEG: Natural Environment, Agriculture and Forestry.

\section{Compliance with ethical standards}

Conflict of interest The authors declare that they have no conflict of interest.

Open Access This article is licensed under a Creative Commons Attribution 4.0 International License, which permits use, sharing, adaptation, distribution and reproduction in any medium or format, as long as you give appropriate credit to the original author(s) and the source, provide a link to the Creative Commons licence, and indicate if changes were made. The images or other third party material in this article are included in the article's Creative Commons licence, unless indicated otherwise in a credit line to the material. If material is not included in the article's Creative Commons licence and your intended use is not permitted by statutory regulation or exceeds the permitted use, you will need to obtain permission directly from the copyright holder. To view a copy of this licence, visit http://creativecommons.org/licenses/by/4.0/.

\section{References}

Aihua L, Jianxin D, Haibing C, Yangyang C, Jun Z (2012) Friction and wear properties of TiN, TiAlN, AlTiN and CrAlN PVD nitride coatings. Int J Refract Met H 31:82-88. https://doi.org/10.1016/j. ijrmhm.2011.09.010

Altgen M, Adamopoulos S, Militz H (2017) Wood defects during industrial-scale production of thermally modified Norway spruce and Scots pine. Wood Mater Sci Eng 12:14-23. https://doi. org/10.1080/17480272.2014.988750

Axelsson A (2012a) Effect of planing on warp in Scots Pine (Pinus sylvestris). Wood Mater Sci Eng 7:154-161. https://doi. org/10.1080/17480272.2012.669408

Axelsson A (2012b) Rectangularity of planed Scots pine (Pinus sylvestris) planks. Wood Mater Sci Eng 8:145-151. https://doi. org/10.1080/17480272.2012.749300

Barshilia HC, Selvakumar N, Deepthi B, Rajam KS (2006) A comparative study of reactive direct current magnetron sputtered CrAlN and CrN coatings. Surf Coat Technol 201:2193-2201. https://doi.org/10.1016/j.surfcoat.2006.03.037

Beer P, Djouadi MA, Sokolowska A, Lambertin M, Czyzniewski A, Precht W (1999) Antiabrasive coatings in a new applicationwood rotary peeling process. Vacuum 53:363-366. https://doi. org/10.1016/S0042-207X(99)00110-4

Benlatreche Y, Nouveau C, Aknouche H, Imhoff L, Martin N, Gavoille J, Rousselot C, Rauch JY, Pilloud D (2009) Physical and mechanical properties of CrAlN and CrSiN ternary systems for wood machining applications. Plasma Process Polym 6:S113-S117. https://doi.org/10.1002/ppap.200930407

Berthier S, Kokutse AD, Stokes A, Fourcaud T (2001) Irregular heartwood formation in maritime pine (Pinus pinaster Ait): consequences for biomechanical and hydraulic tree functioning. Ann Bot 87:19-25. https://doi.org/10.1006/anbo.2000.1290

Bobzin K (2017) High-performance coatings for cutting tools. CIRP J Manuf Sci Technol 18:1-9. https://doi.org/10.1016/j.cirpj .2016 .11 .004

Bustos AC, Moya LC, Lisperguer MJ, Viveros ME (2010) Effect of knife wear on the gluability of planed surfaces of radiata pine. Wood Fiber Sci 42:185-191

Darmawan W, Usuki H, Quesada J, Marchal R (2008) Clearance wear and normal force of TiN-coated P30 in cutting hardboards and wood-chip cementboards. Holz Roh Werkst 66(89-9):7. https://doi.org/10.1007/s00107-007-0213-5

Darmawan W, Usuki H, Gottlöber C, Marchal R (2010) Wear characteristics of multilayer coated cutting tools in milling particleboard. For Prod J 60:615-621. https://doi.org/10.13073 /0015-7473-60.7.615

Darmawan W, Azhari M, Rahayu IS, Nandika D, Dumasari L, Malela I, Nishio S (2018) The chips generated during up-milling and down-milling of pine wood by helical router bits. J Indian Acad Wood Sci 15:172-180. https://doi.org/10.1007/s1319 6-018-0223-4

Darmawan W, Azhari M, Rahayu IS, Nandika D, Putri RL, Malela SN (2019) The chips generated during up milling and down milling of pine wood by helical router-bits. Wood Res 64:691-703 
Davim JP (ed) (2013) Wood machining. Wiley, London

Djouadi MA, Beer P, Marchal R, Sokolowska A, Lambertin M, Precht W, Nouveau C (1999) Antiabrasive coatings: application for wood processing. Surf Coat Technol 116-119:508-516. https:// doi.org/10.1016/S0257-8972(99)00236-4

Faga MG, Settineri L (2006) Innovative anti-wear coatings on cutting tools for wood machining. Surf Coat Tech 201:3002-3007. https ://doi.org/10.1016/j.surfcoat.2006.06.013

Fahrussiam F, Praja IA, Darmawan W, Wahyudi I, Nandika D, Usuki H, Koseki S (2016) Wear characteristics of multilayer-coated cutting tools in milling wood and wood-based composites. Tribol Ind 38:66-73

Farjon A (2005) Pines drawings and descriptions of the Genus Pinus, 2nd edn. Brill, Leiden

Fuentes GG, Rodriguez R, Avelar-Batista JC, Housden J, Montalá F, Carreras LJ, Cristobal AB, Damborenea JJ, Tate TJ (2005) Recent advances in the chromium nitride PVD process for forming and machining surface protection. J Mater Process Technol 167:415-421. https://doi.org/10.1016/j.jmatprotec.2005.06.011

Gilewicz A, Warcholinski B, Szymanski W, Grimm W (2013) $\mathrm{CrCN} / \mathrm{CrN}+$ ta-C multilayer coating for applications in wood processing. Tribol Int 57:1-7. https://doi.org/10.1016/j.tribo int.2012.07.006

Grobelny T (1999) Thermo-mechanical condition of the tool blade in the process of milling wood and wood materials. Thesis, Warsaw University of Life Science, Warsaw

ISO 4287:1997 (1997) Geometrical product specifications (GPS)— surface texture: profile method: terms, definitions and surface texture parameters. International Organization for Standardization, Geneva

ISO 25178-2:2012 (2012) Geometrical product specification (GPS)—surface texture: areal-part 2: terms, definitions and surface texture parameters. International Organization for Standardization, Geneva

Kazlauskas D, Keturakis G (2015) Wear of TiCN, CrN and DLC coated tungsten carbide router cutters during oak wood milling. In: Proceedings of 20th international scientific conference: Mechanika. Kaunas University of Technology Kaunas, Lithuania, pp 139-142 https://www.researchgate.net/publicatio n/308163566_Wear_of_TiCN_CrN_and_DLC_Coated_Tungs ten_Carbide_Router_Cutters_During_Oak_Wood_Milling

Keturakis G, Bendikiene R, Baltrusaitis A (2017) Tool wear evolution and surface formation in milling various wood species. BioResources 12:7943-7954. https://doi.org/10.15376/biore s.12.4.7943-7954

Kong Y, Tian X, Gong C, Chu PK (2018) Enhancement of toughness and wear resistance by $\mathrm{CrN} / \mathrm{CrCN}$ multilayered coatings for wood processing. Surf Coat Technol 344:204-213. https:// doi.org/10.1016/j.surfcoat.2018.03.027

Liu C, Liu Z, Wang B (2018) Modification of surface morphology to enhance tribological properties for CVD coated cutting tools through wet micro-blasting post-process. Ceram Int 44:34303439. https://doi.org/10.1016/j.ceramint.2017.11.142

Malkoçoğlu A (2007) Machining properties and surface roughness of various wood species planed in different conditions. Build Environ 42:2562-2567. https://doi.org/10.1016/j.buildenv.2006.08.028

Marinich A, Powell K (2017) Scots pine (Pinus sylvestris L.) Best Management Practices in Ontario. Ontario Invasive Plant Council, Peterborough

Nieslony P, Cichosz P, Krolczyk GM, Legutko S, Smyczek D, Kolodziej M (2016) Experimental studies of the cutting force and surface morphology of explosively clad $\mathrm{Ti}$-steel plates.
Measurement 78:129-137. https://doi.org/10.1016/j.measuremen t.2015.10.005

Nouveau C, Jorand E, Decès-Petit C, Labidi C, Djouadi MA (2005) Influence of carbide substrates on tribological properties of chromium nitride coatings: application to wood machining. Wear 258:157-165. https://doi.org/10.1016/j.wear.2004.09.034

Nouveau C, Labidi C, Ferreira Martin JP, Collet R, Djouadi MA (2007) Application of CrAlN coatings on carbide substrates in routing of MDF. Wear 263:1291-1299. https://doi.org/10.1016/j. wear.2006.12.069

Nouveau C, Labidi C, Collet R, Benlatreche Y, Djouadi MA (2009) Effect of surface finishing such as sand-blasting and CrAlN hard coatings on the cutting edge's pelling tools' wear resistance. Wear 267:1062-1067. https://doi.org/10.1016/j.wear.2009.01.045

Okai R, Tanaka C, Iwasaki Y (2006) Influence of mechanical properties and mineral salts in wood species on tool wear of high-speed steels and stellite-tipped tools-consideration of tool wear of the newly developed tip-inserted band saw. Holz Roh Werkst 64:4552. https://doi.org/10.1007/s00107-005-0015-6

Pinheiro D, Vieira MT, Djouadi MA (2009) Advantages of depositing multilayer coatings for cutting wood-based products. Surf Coat Technol 203:3197-3205. https://doi.org/10.1016/j.surfc oat.2009.03.052

Porankiewicz B, Jozwiak K, Wieczorek D, Idzikowski I (2015) Specific wear on the rake face made of sintered carbide cutting edge during milling of laminated wood. Eur J Wood Prod 73:35-41. https:// doi.org/10.1007/s00107-014-0862-0

Reiter AE, Derflinger VH, Hanselmann B, Bachmann T, Sartory B (2005) Investigation of the properties of $\mathrm{Al}_{1-\mathrm{x}} \mathrm{Cr}_{\mathrm{X}} \mathrm{N}$ coatings prepared by cathodic arc evaporation. Surf Coat Technol 200:2114 2122. https://doi.org/10.1016/j.surfcoat.2005.01.043

Sandberg D, Söderström O (2006) Crack formation due to weathering of radial and tangential sections of pine and spruce. Wood Mater Sci Eng 1:12-20. https://doi.org/10.1080/17480270600644407

Schmithüsen F, Kaiser B, Schmidhauser A, Mellinghoff S, Perchthaler K, Kammerhofe AW (2015) Entrepreneurship and management in forestry and wood processing: principles of business economics and management processes. Routledge, Abingdon

Stout KJ, Sullivan PJ, Dong WP, Mainsah E, Luo N, Mathia T, Zahouani H (1993) The development of methods for the characterization of roughness in three dimensions, EUR 15178 EN (Final Report), BCR, Brussels

Twardowski P, Legutko S, Krolczyk GM, Hloch S (2015) Investigation of wear and tool life of coated carbide and cubic boron nitride cutting tools in high speed milling. Adv Mech Eng. https://doi. org/10.1177/1687814015590216

Walker JCF, Butterfield BG, Harris JM, Langrish TAG, Uprichard JM (2013) Primary wood processing: principles and practice. Springer Science \& Business Media, London

Warcholinski B, Gilewicz A (2011) Multilayer coatings on tools for woodworking. Wear 271:2812-2820. https://doi.org/10.1016/j. wear.2011.05.048

Warcholinski B, Gilewicz A, Ratajski J (2011) $\mathrm{Cr}_{2} \mathrm{~N} / \mathrm{CrN}$ multilayer coatings for wood machining tools. Tribol Int 44:1076-1082. https ://doi.org/10.1016/j.triboint.2011.05.004

Publisher's Note Springer Nature remains neutral with regard to jurisdictional claims in published maps and institutional affiliations. 